ENCUESTA 



\section{ENCUESTA SOBRE NACIÓN Y SUPRANACIONALIDAD}

\section{PRESENTACIÓN}

Desde sus inicios, esta revista ha querido atender, como su nombre indica, tanto a la teoría como a la realidad constitucional, y esto se ha reflejado siempre en los temas tratados y en los enfoques adoptados para ello. La encuesta que abre este número también tiene esa pretensión, aunque su rúbrica pueda llevar a pensar que se trata sobre todo de un cuestionario diseñado desde preocupaciones fundamentalmente teóricas. Sin embargo, no es así. Esta encuesta se suma a otros consultas y trabajos ya publicados que tienen relación estrecha con nuestra forma de organización política en general, y territorial en particular, y con los problemas que se plantean respecto a ella.

En esta ocasión, a diferencia de otras en las que han primado aspectos más concretos, hemos buscado una aproximación desde un ángulo diferente, más general, invitando a la reflexión sobre el concepto de «nación», su origen, evolución histórica y significado actual, con el propósito de que esa reflexión nos pueda arrojar cierta luz no solo sobre el significado jurídico constitucional que debemos darle sino también sobre las dinámicas político constitucionales que genera.

El punto de arranque de esta encuesta se sitúa, pues, en el concepto de «nación» que, como se sabe, jugó un papel determinante en el origen del constitucionalismo europeo continental. Pero nos interesa, más que el punto de partida, la evolución posterior, porque, más tarde, como también se sabe, este concepto sirvió de apoyo a la aparición de los movimientos nacionalistas y fue parcialmente sustituido por el de «pueblo» a medida que se fueron aceptando los postulados del Estado democrático. La comprensión de este concepto y su significado no resulta en absoluto sencilla, ya que para ello hay que atender al plano de las construcciones teóricas, al de los hechos histórico-políticos y al estrictamente jurídico.

A diferencia de la mayoría de los textos constitucionales de los países de nuestro entorno, la Constitución Española recoge expresamente la idea de nación, tanto en el preámbulo como en el texto (art. 2), y por ello nos interesa detenernos en el significado jurídico constitucional que cabe atribuir a dicha idea en nuestro 
concreto ordenamiento jurídico. Esto obliga, como es obvio, a plantearnos también el significado que cabe atribuir al término «nacionalidades», recogido en el mismo art. 2 CE.

Por último, la realidad de los actuales Estados constitucionales se ha transformado profundamente con el proceso de integración europea, y esto se pone de manifiesto también en relación con la idea de nación. De hecho, la supranacionalidad es precisamente una nota definitoria de tal proceso, entendida, en cierto modo, como la superación de una determinada idea de nación e incluso de los nacionalismos que se apoyan en ella. Quizás sea esta línea la que haya que explorar aún con algo más de profundidad, por eso nos planteamos en esta encuesta qué cabe entender por «supranacionalidad» en el ámbito de la Unión Europea y qué consecuencias tiene tal idea, si las tiene, sobre cómo hayamos de entender hoy el concepto de nación a nivel estatal.

El resultado de nuestras inquietudes se ha plasmado en un conjunto de preguntas que, como siempre, un grupo de reconocidos expertos han tenido a bien contestar. Como el lector podrá comprobar, sus respuestas a buen seguro nos ayudarán a formarnos una idea más clara de uno de los elementos fundamentales que están en la base de la construcción de cualquier proyecto de organización política. A todos los encuestados queremos agradecer muy sinceramente su generosa colaboración con la revista y el esfuerzo dedicado a ofrecernos, en pocas páginas, reflexiones claras y precisas sobre temas tan complejos.

\section{CUESTIONES}

1. La idea de nación está en el origen del primer constitucionalismo francés. A su juicio ¿qué debemos recordar hoy sobre el papel que ba desempeñado la idea de nación en el desarrollo bistórico del constitucionalismo? ¿Y de la influencia en ese desarrollo de los movimientos nacionalistas que surgieron a partir de él?

2. ¿Cuál es, en su opinión, la relación actual entre los conceptos de constitución y nación?

3. En el caso de España, y a diferencia de los textos constitucionales de la posguerra europea, nuestra constitución se refiere a la nación en el preámbulo, además de hacerlo también en el art. 2 ¿Cómo cree que deben interpretarse estas referencias? ¿Qué significado jurídico constitucional cabe atribuirles?

4. ¿Qué relevancia cabe atribuir a las contraposiciones conceptuales que establece el art. 2 entre nación española, nacionalidades y regiones?

5. En el proceso de integración supranacional que se inició en Europa tras la Segunda Guerra Mundial ¿qué significado se atribuyó a la idea de supranacionalidad? ¿En qué medida se entendió como la superación de las ideas de nación y nacionalismo?

6. Setenta años después ¿ se puede seguir entendiendo del mismo modo la supranacionalidad europea? ¿Cómo se explica boy la relación entre la idea de nación y el proyecto supranacional europeo? 


\section{ENCUESTADOS}

BENITO ALÁEZ CORRAL, Catedrático de Derecho Constitucional, Universidad de Oviedo

PALOMA BIGLINO CAMPOS, Catedrática de Derecho Constitucional, Universidad de Valladolid

ROBERTO BLANCO VALDÉS, Catedrático de Derecho Constitucional, Universidad de Santiago de Compostela

JOSEP M. ${ }^{a}$ CASTELLÁ ANDREU, Catedrático de Derecho Constitucional, Universidad de Barcelona

ALBERTO LÓPEZ BASAGUREN, Catedrático de Derecho Constitucional, Universidad del País Vasco

ESTHER SEIJAS VILLADANGOS, Catedrática de Derecho Constitucional, Universidad de León

\section{RESPUESTAS}

1. La idea de nación está en el origen del primer constitucionalismo francés. A su juicio ¿qué debemos recordar boy sobre el papel que ha desempeñado la idea de nación en el desarrollo histórico del constitucionalismo? ¿Y de la influencia en ese desarrollo de los movimientos nacionalistas que surgieron a partir de él?

\section{BENITO ALÁEZ CORRAL}

Como es sabido, las revoluciones ilustradas, incluida la francesa, construyen a partir de las nociones filosófico-políticas de estado de naturaleza y de contrato social la idea de Estado que se orienta a la garantía de los derechos y libertades naturales. La igualdad natural, consustancial a esta visión del individuo, era incompatible con los privilegios y jerarquías sociopolíticas del Antiguo Régimen y su concepto de nación como conjunto de súbditos. La forma de superarlo era construir un concepto de sujeto colectivo (Pueblo/Nación) que agrupase a todos aquéllos que, por ser parte del contrato social, se integraban plenamente en la comunidad política a la que pertenecían mediante la apertura a los mismos de un igual disfrute de los derechos civiles y una potencial capacidad de participación política, reservada durante siglos a unas minorías aristocráticas y eclesiásticas. En este punto, el concepto de ciudadano va a desempeñar, sobre todo en el pensamiento revolucionario anglosajón y francés, una función incluyente como virtud cívica que permite unir a los individuos a través del reconocimiento de unos derechos civiles y de participación política más allá del mero vínculo legal de sujeción que había generado la nacionalidad para el Estado absoluto. El ciudadano, en otras palabras, comienza a ser identificado con el individuo integrante de la Nación o del Pueblo soberano, y para ello tiene que ser igual a los demás por lo 
menos en su titularidad abstracta de la soberanía — cuando no también en su concreta capacidad de ejercer por sí mismo una fracción de la misma- La titularidad del poder, y por tanto la plena pertenencia a la comunidad política, corresponde a los individuos integrantes de la Nación y la otorga precisamente la ciudadanía.

Aunque en un principio algunos movimientos revolucionarios, como el francés, tuvieran un carácter universalista y desligasen el concepto de Nación de su sentido étnico-cultural histórico, los textos constitucionales contribuyen a su etnificación o culturalización a través de los efectos homogeneizadores que poseen los criterios constitucionalmente establecidos para la adquisición de la nacionalidad. El dogma de la soberanía popular/nacional termina remitiendo a un sujeto prejurídico, presuntamente homogéneo y heredado del Antiguo Régimen, al que ahora se convierte en titular de la soberanía y cuyas características homogeneizadoras no eran tanto la consecuencia como la causa de ser un sujeto unitario. De ahí que, aunque los criterios de atribución de la nacionalidad y la ciudadanía se distingan durante el período revolucionario, en la práctica se aproximarán paulatinamente durante el siglo XIX, lo que llevará a una construcción no siempre democrática del sujeto nacional de la soberanía, no sólo por la construcción étnico-cultural de la nacionalidad, de la que la ciudadanía pasa a ser un círculo concéntrico sumamente reducido, sino también porque, al reafirmarse su parcial vinculación funcional, se introducen nuevos criterios de exclusión del ejercicio de esta última para quienes ya son nacionales.

\section{PALOMA BIGLINO CAMPOS}

La primera de las preguntas de este apartado se refiere a la idea de nación que aparece en Francia durante el primer constitucionalismo. Esta delimitación permite prescindir, por ahora, de conceptos anteriores, como es el medieval, que hacía referencia a un grupo con lengua común y originario de la misma localidad, así como de otras nociones posteriores, como el que prosperará durante el s. XIX, y determinará la construcción de algunos Estados, no sólo en Europa sino también en América. La concreción de la pregunta permite, además, dejar de lado otra idea de nación más sociológica, que sólo hace referencia a un grupo humano, dotado de características comunes, como puede ser la tradición histórica, la cultura o la lengua.

La nación que interesa, pues, es la que enuncia Sieyès en ¿Qué es el Tercer Estado?, donde se define como «un cuerpo de asociados que viven bajo una ley común y representados por una misma legislatura». Se trata de una idea de carácter jurídico-político porque exige, en primer lugar, que la nación esté unificada por las mismas normas; en segundo lugar, que dichas normas no sean impuestas desde fuera sino elaboradas por una asamblea que represente a quienes componen dicha nación. 
Al inicio de la revolución francesa, Sieyès avanza los principios que luego se proclamarán en la Declaración de Derechos de 1789 y en la Constitución de 1791. La soberanía (única, indivisible, inalienable e imprescriptible) radica en la nación y ningún otro grupo social o individuo puede atribuirse su ejercicio. Todos los poderes emanan de ella y sólo pueden ejercerse por delegación, especialmente en el Parlamento. Conlleva la idea de igualdad, no solo porque quienes forman parte de la nación tienen derecho a participar en la elaboración de la ley, sino también porque la ley ha de tratar a todos por igual, tanto cuando premia, como cuando castiga.

Es claro que, al enunciar estos principios, Sieyès está reivindicando el protagonismo en el sistema político de un grupo social determinado, esto es, el tercer estado. Ahora bien, no hay nada en su obra ni en la experiencia revolucionaria francesa que anude, como sucederá más adelante, la idea de nación con hechos identitarios. Ese será un fenómeno muy posterior al que habrá que hacer referencia más adelante. Por ahora, conviene señalar que, en esa primera etapa, la idea de nación no aparece asociada a las posteriores reivindicaciones nacionalistas.

La concepción originaria de nación ha tenido un papel nuclear en el desarrollo histórico del constitucionalismo. Sirvió para proclamar un nuevo titular de soberanía, lo que supuso acabar con la monarquía absoluta. Incorporó, además, los principios de igualdad y libertad, lo que puso fin a la heterogeneidad normativa y los privilegios que caracterizaban al antiguo régimen. Ahora bien, con el tiempo, la misma idea de nación irá perdiendo ese contenido innovador y empezará a demostrar sus propias limitaciones.

Desde sus propios orígenes, el concepto de nación al que se hace referencia está afectado por un problema nuclear, que radica en su excesiva indeterminación. En efecto, ni precisa quiénes forman parte de la nación ni quiénes tienen capacidad de representarla. Esta ambigüedad hizo posible transformar el concepto revolucionario de nación en otro de corte conservador, destinado a limitar la representatividad del sistema político. Durante todo el siglo XIX y parte del $\mathrm{xx}$, se entiende que la buena marcha de la nación no afectaba a todos por igual, por lo que no todos estaban capacitados para expresar su voluntad. Por eso, fue compatible con el sufragio censitario y con la privación del derecho de voto a las mujeres y a las personas de color. Quienes no eran propietarios, varones o blancos, según las épocas históricas, no tenían intereses en la nación, por lo que estaban representados «virtualmente» por el órgano elegido exclusivamente por quienes reunían dichas condiciones.

El salto a la escena política de los primeros movimientos de masas y el reconocimiento del sufragio universal suponen un cambio en la definición de soberanía, que deja de ser nacional para pasar a ser popular. Las transformaciones que genera esta nueva concepción se analizarán en el siguiente apartado. Por ahora, conviene retomar la afirmación que antes se anticipaba y que consistía en recordar que la idea de nación adquiere otro sentido durante el siglo XIX, cuando da lugar a reivindicaciones de corte nacionalista. 
Aunque hay muchos movimientos diferentes que formulan esas demandas, todos parten de la idea de Sieyès, porque reivindican la voluntad de un grupo humano de convertirse en la comunidad política de un Estado. Reclaman, pues, la titularidad de la soberanía dentro de su territorio. Ahora bien, esta idea de nación ya no se usa frente al poder absoluto del monarca, sino frente a un poder que se considera extranjero. Fue la idea de nación que inspiró la creación de Italia, Alemania o Irlanda y es la que sigue inspirando a aquellos movimientos nacionalistas que, en España como otros países de Europa, reclaman independencia.

Al tener el mismo origen, presentan problemas similares a los que afectaban a la idea de nación que prosperó con la revolución francesa, esto es, su indeterminación. Ya Renán, en su conferencia de la Sorbona de 1882, señalaba que ningún elemento basta para crear una nación, porque ninguno de ellos es común a todas las naciones que han existido o existen. Ante la ausencia de esos elementos objetivos, el autor apuesta por configurar la nación como un mero sentimiento subjetivo, esto es, como «un alma, un principio de espiritual». En definitiva, como señala Hobsbawm, remitiéndose a Renner, la pertenencia de un individuo a una nación es equiparable a la pertenencia a una confesión religiosa.

No dudo que este significado de la nación, como «comunidad imaginada», en la expresión de Anderson, pueda ser de vital importancia para muchos. Pero, como reconoce $\mathrm{P}$. Costa, no sólo hay que tener en cuenta aquello que la nación es sino, sobre todo, lo que se hace con dicho concepto a la hora de abordar conflictos sociales.

La multifuncionalidad del concepto de nación, derivado de su indeterminación, hizo posible que, en determinados momentos, inspirara movimientos populares de corte liberal-democrático, como ocurrió en Italia durante el Risorgimento. Pero también propició que, en otras circunstancias, diera pie a reacciones autoritarias como ocurrió en la Italia de Mussolini o la Alemania de Hitler.

Este no es un problema que se haya dado sólo en el pasado, sino que está ocurriendo en la actualidad. Basta con consultar los preámbulos de las Constituciones húngaras y polacas para constatar que la idea de nación constituye el sustrato sobre el que se asientan los nuevos populismos. Así, sirve para identificar a un grupo humano dotado de caracteres genuinos, para excluir a quienes no comparten dichos requisitos y, finalmente, para aglutinar las fuerzas del país en contra de la acción de las instituciones comunitarias en defensa de los valores proclamados por el art. 2 del Tratado de la Unión. La protección del Estado de Derecho, de los derechos fundamentales y del principio democrático se considera una intromisión «extranjera» que vulnera las creencias inherentes a las naciones internas.

A veces, el nacionalismo enlaza con otras formas de populismo. Puede dar lugar, como está sucediendo en España, a afirmar la preexistencia de un grupo humano que comparte lengua, tradición o cultura. Este reconocimiento no tiene nada que objetar, porque aparece en el propio preámbulo de la Constitución, que afirma la pluralidad de pueblos de España. El problema aparece cuando dicho grupo se contempla como nación, dotada de la voluntad de transformarse en 
Estado al margen de lo dispuesto en las normas jurídicas. Se acrecienta cuando se excluye de ese grupo a quienes no comparten esas características comunes; culmina cuando la nación se encarna en un líder, o conjunto de líderes que, por expresar esa voluntad, se consideran legibus solutus.

\section{ROBERTO BLANCO VALDÉS}

En efecto, la idea de nación está íntimamente vinculada a la Revolución liberal y a una de sus más directas y sobresalientes consecuencias: el constitucionalismo. El término nación sólo se menciona un par de veces en la Constitución de los Estados Unidos de América —en la sección octava del artículo 1. - al hacer referencia a los poderes del Congreso para reglamentar el comercio con las naciones extranjeras y para definir y castigar la piratería y otros delitos graves cometidos en alta mar, así como las violaciones del derecho de las naciones (Law of Nations). La razón de ello es fácil de explicar: cuando el texto norteamericano hace referencia a lo que las Constituciones revolucionarias europeas denominan la Nación utiliza otro término, el de la Unión: así, por ejemplo, ya en el preámbulo, cuando se proclama que se estatuye y sanciona la Constitución para los Estados Unidos de América con el fin, entre otros, de formar una más perfecta Unión. El propio texto se referirá luego al derecho de la Unión, a los estados de la Unión o al Congreso de la Unión. Aunque no es este el lugar para detenerse en la cuestión, ese cambio (Unión en lugar de Nación) expresa con toda claridad el profundo contraste existente entre el proyecto político y constitucional de los norteamericanos - la construcción de un Estado federal — y el de las naciones europeas que, en el pleno sentido de ese término, surgían con la Revolución: la transformación de las antigua monarquías absolutas en Estados unitarios donde la centralización trataba de acabar con la pluralidad de ordenamientos y poderes existentes en la sociedad feudo-estamental. Como escribió en su día Tocqueville en El Antiguo Régimen y la Revolución, "apercibiréis un poder central inmenso que ha atraído y absorbido en su unidad todas las parcelas de autoridad y de influencia que estaban antes dispersas en una multitud de poderes secundarios, de clases, de profesiones, de familias y de individuos y como esparcidas por todo el cuerpo social. No se había visto en el mundo un poder semejante desde la caída del Imperio romano. La Revolución ha creado este poder nuevo, o más bien éste ha surgido por sí mismo de las ruinas que la Revolución ha hecho».

Ese nuevo poder, el Estado constitucional —en sentido estricto «el primer poder absoluto de la historia», como, con razón, ha explicado Javier Pérez Royo en su Introducción a la teoría del Estado - tiene como base esencial un concepto que cambia de sentido respecto del pasado y sobre el que se sostiene la construcción histórica del movimiento liberal y constitucional. Así puede verse en la Declaración de Derechos del Hombre y del Ciudadano (cuyo artículo 3..$^{\circ}$ dispone que «la nación es esencialmente la fuente de toda soberanía», de modo que «ningún 
individuo ni ninguna corporación pueden ser revestidos de autoridad alguna que no emane directamente de ella») y en el primero de los textos europeos del constitucionalismo revolucionario, la Constitución francesa de 1791, que recoge el término nación (o su derivado nacional) hasta en un total de 74 ocasiones con un sentido bien preciso, del que deja constancia ya el tercero de sus títulos: atribuir a la nación el supremo poder del Estado ( «La Soberanía es una, indivisible, inalienable e imprescriptible. Pertenece a la Nación; ninguna sección del pueblo ni ningún individuo puede atribuirse su ejercicio») y convertirla en la fuente de todos los poderes públicos: «La Nación, de la que emanan todos los Poderes, no puede ejercerlos más que por delegación».

Será, sin embargo, la Constitución española de 1812 la que expresará de un modo más preciso y claro la doble significación fundamental que pasará a tener el concepto de nación para el constitucionalismo liberal. De un lado, la nación es un espacio físico y político que sustituye al reino, con el que se identificaba hasta entonces un espacio físico y político que era indistinguible - lo más parecido a una propiedad - de los monarcas absolutos. El texto gaditano determina así, no casualmente en su artículo 1. ${ }^{\circ}$, que la «la Nación española es la reunión de todos los españoles de ambos hemisferios», es decir, un conjunto de personas — de nacionales- que habitan un determinado territorio. Por si ello no hubiera quedado suficientemente claro, el artículo $2 .^{\circ}$ de la Constitución, añade, acto seguido, que «la Nación española es libre e independiente, y no es ni puede ser patrimonio de ninguna familia ni persona». Pero, además, de otro lado, la nación es la titular de la soberanía, es decir, del máximo poder del nuevo Estado liberal, que según la Constitución «reside esencialmente en la Nación y por lo mismo pertenece a ésta exclusivamente el derecho de establecer sus leyes fundamentales». El Conde de Toreno, diputado constituyente, explicó en la sesión de Cortes de 28 de agosto de 1812 que «esencialmente expresa que este derecho coexiste, ha coexistido y coexistirá siempre con la nación mientras no sea destruida; envuelve además esta palabra esencialmente la idea de que es innegable y cualidad de la que no puede desprenderse la nación como el hombre de sus cualidades físicas; porque nadie, en efecto, podría hablar por mí, respirar por mí: así jamás delega el derecho y sólo el ejercicio de la soberanía».

Por lo que se refiere al papel de la nación en el desarrollo histórico del constitucionalismo, ambas realidades resultan, como acabo de apuntar, inseparables, tanto desde el punto de vista histórico como conceptual. La nación es la base física (un territorio) y política (un conjunto de ciudadanos) del Estado y es la fuente de sus poderes, cuyas reglas esenciales de funcionamiento y su recíproca limitación se contienen en la Constitución, que regula también la relación entre los ciudadanos y los poderes estatales. Pero la Constitución expresa, a su vez, la propia existencia de un poder político estatal autónomo que se basa en los dos principios esenciales, que ya recogía el artículo 16 de la Declaración de los Derechos del Hombre y del Ciudadano, y sin los cuales la Constitución misma no podría existir: la garantía de la separación de poderes y del reconocimiento de los derechos 
y libertades. Por ello, en el devenir histórico, la aparición de los Estados ha venido estando íntimamente ligada a la existencia de una Constitución que los define como tales, aun en el caso de que aquella no fuese, en la terminología de Karl Loewenstein, una constitución normativa sino una meramente nominal o semántica, es decir, una Constitución que no responde en realidad al desarrollo efectivo del proceso político del Estado-nación de que se trate en cada caso. Basta, para constatarlo, comprobar como la práctica totalidad de los países que hoy componen la Comunidad internacional tienen una Constitución (pueden consultarse con facilidad en la magnífica web de Constitution Finder) aunque muchas de ellas no sean más que el trampantojo tras el que se esconde una forma de ejercicio de poder que para nada responde a los criterios materiales de una Constitución digna de tal nombre.

Finalmente, la influencia de los movimientos nacionalistas en el desarrollo histórico del constitucionalismo se deduce en gran medida de lo ya apuntado. Nación y Constitución surgen históricamente de un modo paralelo, porque en grandísima medida las primeras revoluciones liberales fueron también revoluciones nacionales: así sucedió en Estados Unidos, cuya Constitución de 1787, aun hoy vigente, fue el punto de culminación de una revolución y una guerra anticolonial; y así aconteció, y no es más que otro ejemplo, en España, donde la Constitución de 1812 surgió en el contexto de una guerra de liberación nacional contra un ocupante extranjero. Cuando Bélgica se independiza de los Países Bajos aprueba su Constitución de 1831. Con posterioridad pueden señalarse otros dos ejemplos altamente significativos: los de Alemania e Italia, que nacen como naciones unificadas en 1870 al mismo tiempo que sus Constituciones: la del primer Imperio alemán, de 1871, y el Estatuto Albertino de 1848, adoptado como primera Constitución de la Italia Unida. Y aún más tarde los casos de Checoslovaquia, Austria, Polonia y Albania, que nacen como Estados independientes en los primeros años 20 y aprueban cada uno de ellos sus Constituciones nacionales. Finalmente, y para cerrar este brevísimo recorrido histórico, todos los países que acceden a la independencia tras el proceso descolonizador posterior a la Segunda Guerra Mundial entrarán, entonces, de la mano de su aparición como Estados en el mundo constitucional, pues las Constituciones son también, aunque no sólo, una señal de identidad de la existencia de un país en la comunidad internacional.

\section{JOSEP M. ${ }^{a}$ CASTELLÁ ANDREU}

En el legado del constitucionalismo liberal democrático ocupa un lugar relevante la vinculación entre nación y constitución. La nación como agrupación de ciudadanos que se autodetermina políticamente a la vez que se autolimita a través de la Constitución. El constitucionalismo francés y el americano difieren, entre otros, en la posición de la ley, en el valor jurídico de la declaración de derechos, o en el alcance y modalidades de control judicial del poder. Pero ambos asumen 
unos ideales liberal democráticos que se pretenden universales: la limitación del poder político a través de la separación de poderes y la garantía de unos derechos fundamentales. Al mismo tiempo, cada experiencia constitucional es distinta: la Constitución se origina y arraiga en una comunidad política concreta, por lo general preexistente, a la que da su fisonomía (forma de estado y forma de gobierno). Comunidad política, democracia y constitución forman un todo, hasta hoy inescindible: no hay ni democracia ni constitución fuera de la comunidad nacional. Como corolario, el primer constitucionalismo francés crea una ciudadanía libre e igual ante la ley y en derechos.

En España, en Cádiz se impone la impronta constitucional liberal, a la francesa, sobre la tradicional (que aflora no obstante con la denominación histórica de «las Españas», reconocedora de su pluralidad interna) y sobre la federal o americana. Así, la constitución define la «Nación española» como la «reunión de todos los españoles de ambos hemisferios» (art. 1), en la cual reside esencialmente la soberanía (art. 3). Al mismo tiempo, se enumeran los territorios que componen «las Españas» (art. 10), pero sin atribuirles un régimen autónomo.1808 es un momento clave para la cohesión de la identidad nacional española, al levantarse la nación contra la invasión napoleónica, a la que la Constitución de 1812 da forma política y jurídica. Prima la identidad nacional sobre el reconocimiento de las particularidades territoriales (Jorge Vilches, 2008). Ello supone el triunfo de la nación de ciudadanos españoles sobre la nación orgánica y tradicional, como recuerda Ángel Rivero (2011).

Tras algunos intentos fugaces y frustrados a lo largo de los dos últimos siglos, la constitución de 1978 completa el cuatro anterior al afirmar, por un lado, la nación de ciudadanos libres e iguales en derechos y el pueblo español como único sujeto soberano (herencia de Cádiz), y por el otro, junto a ellos, al dar reconocimiento a la autonomía territorial y a la pluralidad de pueblos con sus lenguas, culturas, tradiciones e instituciones (desde el Preámbulo de la Constitución), que será concretado, de forma inmediata, a través del Estado autonómico. Previamente, en 1976 y 1977, los españoles ya habían sentado las bases para el establecimiento de una comunidad política democrática, basada en la supremacía de la ley, expresión de la voluntad soberana del pueblo, y en unos derechos fundamentales que vinculan a todos los órganos del Estado (art. 1 de la Ley para la Reforma Política).

\section{ALBERTO LÓPEZ BASAGUREN}

La idea de nación se incrusta en el constitucionalismo, efectivamente, con la Revolución francesa. Pero esta es solo una de las tradiciones del constitucionalismo, aunque, ciertamente, es la que más influye en nuestra tradición política, especialmente en el s. XIX.

El término 'nación' es muy anterior al movimiento revolucionario francés. Pero en el siglo XVIII es retomado por el pensamiento liberal-revolucionario 
atribuyéndole un estricto significado político: la 'nación' como titular de la soberanía. De esta forma, los revolucionarios y, en general, el liberalismo francés -y quienes beberán de esa tradición - logran articular un titular de la soberanía distinto del Rey. En ese sentido, la 'nación' es el elemento que muestra la ruptura con la Monarquía absoluta y el nacimiento de un nuevo sistema político; el fundamento de la legitimidad del nuevo sistema político. De acuerdo con E. Sieyès la nación es una abstracción («une collectivité abstraite, personne morale transcendante»), que no se identifica con los individuos que la integran, ni pertenece por partes a cada ciudadano, porque no puede atomizarse. Es una ficción jurídica, a la que se atribuye una voluntad única, en cuanto elemento colectivo e indivisible. En esa condición es titular de la soberanía, personificada en el Estado, que es la nación jurídicamente organizada.

El concepto de nación es, por tanto, para los revolucionarios liberales franceses, un concepto estrictamente jurídico-político. Carece, en este sentido, de otras connotaciones y, así, se separa radicalmente de los contenidos tradicionales que se atribuían al uso del término, como indicación del origen comunitario de las personas, en una acepción carente de connotación política.

Pero el desarrollo de la revolución francesa se enfrentará a retos prácticos que transformarán el significado que se atribuye a la idea de nación, pasando de ser un concepto puramente político a ser un concepto también, cuando menos, cultural y lingüístico. El concepto de 'nación' no planteaba, inicialmente, ningún problema en relación con una 'sociedad' en la que convivían varias lenguas locales, en el que las características de lo que luego constituirá el paradigma de la 'nación francesa' - especialmente, la lengua francesa- es solo patrimonio de una élite, especialmente en amplias zonas de Francia. Pero los revolucionarios se encontrarán con que tienen grandes dificultades para lograr que sus ideas lleguen a la gente común, que en muy gran medida no conocía la lengua francesa, en enorme desventaja con las fuerzas contrarrevolucionarias que -especialmente la Iglesia - habían descubierto la gran utilidad del uso de las lenguas locales en la difusión de sus ideas entre esa gente común. Es esa necesidad de llevar las ideas de la Revolución a la población de Francia lo que lleva a transformar un concepto exclusivamente político-jurídico de 'nación' en un concepto con contenido ‘comunitario', en el que destaca el componente lingüístico-cultural.

De esta forma, 'nación' se transformará en un concepto que, junto a su significado jurídico-político, contiene la idea de una comunidad con unas determinadas características sociales y lingüístico-culturales; es decir, la idea de que nación supone, también, homogeneidad cultural y lingüística. Los revolucionarios franceses utilizarán, así, la idea de nación para expandir la lengua francesa como elemento de la identidad nacional. Se impone, así, la idea de nación como comunidad política que, además, debe responder a unas características de homogeneidad lingüístico-cultural.

El liberalismo francés -y europeo continental influido por aquél—, sin embargo, una vez consolidado el nuevo sistema político, se desprendió pronto de 
la idea de nación, quedando la soberanía vinculada al Estado, siendo sustituida, posteriormente, por la idea de 'pueblo', cuando los sistemas constitucionales evolucionan hacia la idea de soberanía popular. Pero la idea de nación, vinculada a la idea de comunidad con características homogéneas, se refuerza políticamente cuando el liberalismo ya no la utiliza — ya no la necesita- desde el punto de vista jurídico, con el desarrollo y fortalecimiento de los Estados-nación, especialmente en Europa, en lo que E. Hobsbawn denominó la 'era de los nacionalismos'.

Esta idea de nación como comunidad con características de homogeneidad lingüístico-cultural, con una historia singular, tomada del romanticismo, y, al mismo tiempo, sujeto al que le corresponde la titularidad de la soberanía es la que adoptarán los nacionalismos de las comunidades diferenciadas integradas en esos Estados-nación, en cuyo seno consideran que se ve frustrado su 'destino nacional'. Es la idea que subyace a lo que se dio en denominar el «principio de las nacionalidades» — 'cada nación su propio Estado’—, adjudicándose el presidente norteamericano Woodrow Wilson la intención de aplicarlo en la reordenación de Europa tras el fin de la Gran Guerra, pero que, de acuerdo con lo expresado en los Fourteen Points que establecían las bases de los Tratados de Paz, solamente se aplicó — relativamente - en la reordenación del fin de los tres grandes imperios (austro-húngaro, otomano y zarista); es decir, en Europa central y oriental, no en Europa occidental.

En cualquier caso, esta idea demostró, por una parte, su casi imposible materialización práctica, por la compleja configuración —salvo excepción- de las sociedades, en las que se imbricaban distintas comunidades en un mismo territorio; por otra, los enormes costes en el ámbito de los derechos humanos que acarrea su aplicación. Como concluía Tony Judt (Postwar. A History of Europe Since 1945), con una ironía provocadora que expresa la gran tragedia vivida, «Thanks to war, occupation, boundary adjustments, expulsions and genocide, almost everybody now lived in their own country, among their own people». Este es el peligro que contiene una idea de nación en la que se vinculan de forma indisoluble la titularidad de la soberanía y la homogeneidad de sus características distintivas, incluída la lingüística y cultural. Y, por esa razón, es necesario separar uno y otro elemento.

\section{ESTHER SEIJAS VILLADANGOS}

El Tribunal Constitucional español ha descrito el término «Nación» como «extraordinariamente proteico» (STC 31/2010, FJ 12). Ese atributo es el punto de partida para responder a esta doble cuestión inicial y alude a la dimensión polisémica con la que se ha utilizado dicha expresión. Los adjetivos que acompañan a la conceptualización o descripción de nación han sido variados: nación política, jurídica, constitucional, cultural, histórica, lingüística, sociológica o religiosa, entre otros. Tratando de ordenarlos y de acotar la explicación conectada 
a los interrogantes formulados, es preciso hacer una distinción inicial entre nación jurídico-constitucional y nación socio-cultural. Cada uno de ellos será la piedra angular para responder, respectivamente, a la primera y segunda cuestión.

En un sentido jurídico la nación es el resultado de un proceso lento que se focaliza en Europa y que llega a su cénit en 1789, cuando de la mano de Emmanuel Sieyès en su opúsculo ¿Qué es el Tercer Estado? se caracteriza como «un cuerpo de asociados que viven bajo una ley común y representados por una misma legislatura».

El prenacionalismo jurídico nos lleva a los escritos de la filosofía política ilustrada y racionalista de los siglos XVII y XVIII de Hobbes y Kant y al liberalismo político que se convirtió en la antesala del proceso revolucionario francés. Tampoco podemos ignorar, como recuerda Shaffer, que desde el siglo XII, poderosas dinastías en Inglaterra - Angevin y Tudor-, y en Francia, - Capetos y Borbones - fueron diseñando un entramado institucional y legal, proyectado sobre unos territorios en los que residían unos pueblos que tenían unos elementos de cohesión y de diferenciación respecto a otros. Ese Nation-Building (europeo-occidental) se ha polarizado en los referentes francés e inglés, pero no puede desdeñar un prenacionalismo español forjado con la lucha frente a la ocupación musulmana (De Blas Guerrero).

En esa acepción jurídica, la nación debe ser entendida como pueblo, conjunto de individuos que residen en un espacio territorialmente acotado y que se someten a un mismo ordenamiento jurídico. Auténtica sinécdoque, puesto que, en esta descripción, la nación coincide con lo que designamos como el Estado (organización resultante del establecimiento de un pueblo sobre un territorio determinado, articulado en torno a un sistema de normas supremo y originario - Seijas-). Esta parte, pueblo, del todo, Estado, conviene en su utilización indistinta y la explicación radica en que a ese elemento estatal pueblo se le atribuye la titularidad de la soberanía, capacidad originaria de crear derecho, y cuya voluntad debe ser expresada en una Constitución. Es decir, la existencia de las Constituciones halla su razón de ser en la nación. Las Constituciones que dotan de estabilidad al Estado tienen una doble finalidad: reconocer los derechos fundamentales a los ciudadanos y garantizar unas instituciones por las que la voluntad popular pueda seguir manifestándose y creando derecho (art. 16, Declaración de Derechos del Hombre y del Ciudadano), una vez superado ese estadio inicial o constituyente.

Así, dentro de esa nación jurídica, podemos diferenciar la nación constituyente y la nación constituida. La nación que ostenta un poder constituyente es el conjunto de individuos libres e iguales que buscan consolidar un marco jurídico estable, Estado, a través del Derecho, elaborando una Constitución. En la acepción como nación constituyente se equipara el pueblo al Estado y el nexo que lo faculta es la Constitución. La nación constituida remite al pueblo como elemento del Estado, que ejercita sus poderes a través de unos procedimientos formales regulados en la Constitución y que se canalizan en las instituciones que legislan, 
ejecutan y juzgan. La nación, el pueblo, no agota su soberanía en el momento constituyente, creador de una Constitución, continuando con su status de soberano, tras su aprobación, soberanía que ha de accionar a través de las instituciones diseñadas en la Constitución.

La verificación de esta acepción jurídica de nación se vincula a la génesis del constitucionalismo democrático, con la Constitución norteamericana de 1787 y con la Declaración de Derechos del Hombre y del Ciudadano, donde se reconoce la atribución de la titularidad de la soberanía al pueblo, que la ejercerá originariamente mediante la promulgación de la Constitución y, posteriormente, a través de los poderes constituidos. El desarrollo del constitucionalismo halla su causa en la acepción jurídica de nación, a la postre nación en sentido jurídico-constitucional.

La nación socio-cultural, o nación en una acepción metajurídica que puede adoptar otros apelativos como histórica, sociológica, lingüística, se refiere a un factor psicológico de pertenencia a una comunidad o grupo que comparte o cree compartir unos atributos comunes. Estos rasgos se refieren a la tradición, a la lengua, a la etnia, a la religión, a las costumbres, o, incluso, a determinadas instituciones jurídicas. Es decir, son factores objetivos u objetivables, a priori. Pero per se son insuficientes, puesto que tienen que estar acompañados por una dosis de subjetividad, por un elemento volitivo, el querer pertenecer a ella e identificarse a partir de esa pertenencia colectiva.

La nación cultural prioriza su configuración orgánica, corporativa, en la que se integran los individuos. Si buscásemos su contraposición a la nación jurídica, la nación cultural se define como natural, inmutable y subjetiva, mientras que la nación jurídica sería artificial, mutable, racional y objetiva, derivando esa objetividad del contenido de las constituciones que se puede reformar, siguiendo los procedimientos en ellas diseñados. El fundamento de la nación jurídica está en el reconocimiento de la libertad y la igualdad de los individuos, mientras que el de la nación cultural radica en un sentimiento de identidad con una comunidad a la que se prioriza.

El nacionalismo cultural se fundamenta en el romanticismo ilustrado, de Herder, Fichte, Savigny, en el liberalismo conservador de Renan o en ideólogos antiliberales como De Maistre o Bonald.

Como conclusión a esta pregunta, la conexión con el Estado de ambas acepciones de nación es bien distinto. La nación jurídico-constitucional viene a coincidir con el Estado, siendo el Estado el creador de la nación, que pese a su artificiosidad asume un nacionalismo a la medida del ciudadano, no del particularismo étnico (Kamenca). La nación cultural, en su base supraindividual, no se ajusta a los presupuestos de un Estado, sino que ha de facultar que, desde esos rasgos propios, los ciudadanos se reconozcan como parte de una unidad más amplia, que puede tener un reconocimiento jurídico, como nacionalidad, como comunidad, pero no como estado soberano. Es una desviación el considerar que toda nación cultural ha de llevar vinculado un derecho de autodeterminación que implique su conversión en Estado. Es en el final de la Primera Guerra Mundial, 
donde un nacionalismo cultural, avivado por el belicismo coyuntural del momento, busca esa confusión con la estatalidad propiciando movimientos nacionalistas que incorporarán a sus proclamas el principio de las nacionalidades formulado por Mancini, según el cual a toda nación le corresponde un Estado y todo Estado debe estar configurado por una sola nación. El error peligroso de convertir a los Estados en culturalmente homogéneos.

Derivar una consecuencia objetiva de unos presupuestos subjetivos como los de la nación cultural abocó a la paradoja de la primera posguerra (Minogue): un intento de arreglar políticamente las aspiraciones de las nacionalidades más pequeñas crearía una situación intolerable para millones de personas, pues es mucho peor ser minoría en un Estado nacionalista cultural, que ser parte de un pueblo, uno de sus muchos gobernados.

2. ¿Cuál es, en su opinión, la relación actual entre los conceptos de constitución y nación?

\section{BENITO ALÁEZ CORRAL}

Hoy en día existe cierta tensión entre un entendimiento estrictamente jurídico-positivo del concepto nación/pueblo, una vez consolidado el constitucionalismo democrático, y un entendimiento político y pre-positivo de este concepto, que considera que el sujeto colectivo de la soberanía tiene una existencia política y jurídica previa y superior a su conformación por el derecho constitucional positivo. Nuestro actual sistema constitucional, por diversas razones históricas en las que no es posible ahondar ahora, se alinea, creo yo, con la primera de las posturas, y en consecuencia ha juridificado el concepto de nación dentro del texto positivizado de la Constitución democrática, lo cual es una garantía de seguridad jurídica y al tiempo de adaptabilidad a los cambios sociales y geopolíticos sin los grilletes de la homogeneización prejurídica del pasado.

El propio Tribunal Constitucional español así lo ha reconocido, por ejemplo, en el fundamento jurídico $3 .^{\circ}$ de la STC $42 / 2014$ con estas palabras «Obvio es que, en tanto que realidad socio-histórica, Cataluña (y España toda) es anterior a la Constitución de 1978. Desde el punto de vista jurídico-constitucional, el "pueblo de Cataluña" invocado por la Declaración integra, sin embargo, un sujeto que se constituye en el mundo jurídico en virtud del reconocimiento constitucional (al igual que sucede con el conjunto del "pueblo español" del que, conforme al art. 1.2 CE, "emanan todos los poderes del Estado")». Por tanto, el pueblo español, trasunto democrático de la nación española, a los efectos de la constitución es un sujeto que se constituye por el reconocimiento constitucional en el art. 1.2 CE. Y, como se ve, esto vale tanto para el pueblo español como para los pueblos/naciones territorialmente más pequeños integrados en el Estado español. 


\section{PALOMA BIGLINO CAMPOS}

Antes se ha mencionado que existen algunas Constituciones que todavía proclaman la soberanía nacional. Más adelante será preciso hacer referencia a la dimensión de la idea de nación en nuestra norma fundamental. Por ahora, es preciso subrayar que muchos Estados, dotados de democracias consolidadas, han renunciado a esa idea para incorporar, como alternativa, el concepto de pueblo.

Este fue el ejemplo norteamericano que, para hacer posible el primer Estado federal, atribuyó el poder constituyente a todo el pueblo de los Estados Unidos. Con ello, se intentó evitar la estéril polémica que dividió a la doctrina europea durante el siglo XIX y parte del XX, consistente en decidir si, en una estructura federal, la soberanía radicaba en la Federación o en los Estados miembros. En la actualidad, países como Italia o la República Federal Alemana sólo hablan de pueblo y de ciudadanos, seguramente para erradicar cualquier intento de repetir las manipulaciones del concepto de nación que caracterizaron a los movimientos autoritarios.

Es cierto que la noción de pueblo puede resultar afectada por cierta indeterminación, ya que, como sucede con la nación, es posible identificarlo con un grupo social dotado de unidad y permanencia y reivindicar para ese grupo humano la soberanía y el poder constituyente. Pero, en este caso, entramos en el mundo de las ficciones. Así, la idea de un poder constituyente, originario y sin límites, tuvo importancia durante la revolución francesa y ha marcado toda la historia constitucional posterior. Pero resulta complejo seguir utilizando esta idea en los Estados democráticos y de Derecho contemporáneos. En efecto, un agregado de personas ni son un pueblo ni puede actuar manifestando una sola voluntad. Antes de que esto suceda y de que pueda elaborarse una constitución de nueva planta, será preciso que las normas decidan quienes forman parte de ese pueblo y los procedimientos en los que debe actuar para expresar su voluntad. Es necesario, al menos, una regla, esto es, la de la mayoría, imprescindible para que la suma de la mayor parte se impute a todos.

En consecuencia, cabe afirmar que el pueblo es, siempre, una creación de las normas jurídicas. Por tal, sólo es posible entender un conjunto de personas dotadas de una situación jurídica especial, en virtud de la cual son titulares de derechos y obligaciones frente al poder público. El pueblo está, pues, compuesto por ciudadanos. Es cierto que, a veces, hay comunidades humanas preexistentes al Derecho, y que este sólo se limita a reconocerlas. Pero también puede suceder que sea el propio Derecho quien cree al pueblo, dotando de unidad a una comunidad humana antes disgregada.

En la actualidad, por ejemplo, no se puede hablar de un pueblo europeo, en tanto que las normas constitutivas de la Unión Europea no lo establecen, ya que solo hacen referencia a los pueblos de Europa. Ahora bien, y desde un punto de vista estrictamente normativo, nada impide que los Tratados creen un pueblo europeo, proclamando su existencia. 
La noción de pueblo es, además, mucho más compatible con las estructuras federales que la idea de nación. Esta última tiene un carácter excluyente porque, precisamente, la voluntad de constituirse en una organización política soberana impide formar parte, o seguir formando parte, de otra. Los conceptos de pueblo y de ciudadano no suscitan estos inconvenientes. En efecto, nada impide que, dentro de la misma organización política, convivan varios pueblos cuyos ciudadanos estén dotados de diferentes estatus jurídicos. Aunque todos comparten un régimen común en materia de derechos y deberes, derivado de su pertenencia al pueblo del Estado, estos pueden modularse según si forman parte de otras organizaciones territoriales. Hay un hecho que demuestra esta realidad: los ciudadanos de la Unión Europea no sólo son titulares de las facultades que les corresponden como ciudadanos de ella, sino también de los que les corresponde por ser nacionales de un Estado miembro y, si este es federal, por formar parte de la región o Estado federado en el que viva.

\section{ROBERTO BLANCO VALDÉS}

Creo que la pregunta ha quedado contestada en gran medida con las consideraciones realizadas previamente, pero añadiré alguna más que me parece relevante. El Estado-nación es sin duda el modelo de organización político-territorial vigente en el mundo contemporáneo, y lo es desde el momento en que comenzó el proceso de consolidación de los Estados-nación en los compases finales del siglo XVIII e iniciales del siglo XIX. Es importante claro, a muchos efectos, la circunstancia de que esos Estados sean centralizados o federales, pero tal contraste no influye en su consideración constitucional, salvo en el hecho de que las Constituciones federales y las que no lo son parten de principios de organización del Estado notablemente diferentes: en esencia, los estados centralizados garantizan la libertad mediante la denominada separación horizontal de poderes (legislativo, ejecutivo y judicial) mientras que los federales añaden la llamada separación vertical entre el poder central y los poderes territoriales. Esa reflexión, en la que insistieron ya a finales del siglo XVIII los autores de El Federalista, es fundamental para entender la esencia misma de los sistemas de naturaleza federal. El propio Madison lo explicará con una admirable claridad cuando, en el número 51 de $E l$ Federalista, procede a contraponer las condiciones de ejercicio del poder, por un lado, en una «república unitaria», en la que «todo el poder cedido por el pueblo es administrado por un solo gobierno» y en la que «se evitan las usurpaciones de poder dividiendo el gobierno en varias ramas independentes entre sí», y, por la otra, «en la república compuesta de América», es decir, en una república federal, en la que «el poder que delega el pueblo está, primeramente, dividido entre dos gobiernos, y después la parte otorgada a cada gobierno está a su vez dividida entre distintas ramas que son independientes unas de las otras». Como consecuencia de tal doble divisón, concluye Madison, «el pueblo goza de una doble seguridad con 
respecto a sus derechos: los diversos gobiernos se controlarán unos a otros, a la vez que cada gobierno se controlará a sí mismo»

Pero si el aludido contraste resulta relevante a los efectos de hacer efectivos los verdaderos objetivos de las Constituciones y del movimiento constitucional que las impulsó desde el triunfo de las Revoluciones liberales, mucha más importancia tiene, en todo caso, para definir la relación entre nación y Constitución, la naturaleza democrática de esta última. Y ello porque la nación, en el sentido propio de tal concepto, es una reunión de ciudadanos - en tanto que tales, libres e iguales_- que conforman un Estado, algo sólo posible cuando estamos en presencia de una Constitución democrática. Desde este punto de vista se ha producido un cambio sustancial en la relación entre nación y Constitución antes y después de la generalización de la democracia, es decir, antes y después de la Segunda Guerra Mundial. Con la excepción británica y de algunos países nórdicos, que aprobaron el sufragio universal (por tanto, de hombres y mujeres) en el primer tercio de la anterior centuria, la mayor parte de los textos constitucionales del siglo XIX y la primera parte del XX reducían de facto la nación a los titulares del derecho de sufragio, lo que determinó durante décadas la relación efectiva entre nación y Constitución. La nación coincide con el pueblo y ambos se incluyen en las Constituciones únicamente cuando éstas y los Estados cuyos poderes regulan se han convertido en democráticos.

\section{JOSEP M. ${ }^{a}$ CASTELLÁ ANDREU}

Hoy la nación y la constitución, como factores indisociables de integración política, están en crisis, en varias zonas del mundo, y singularmente en España. La eclosión y reivindicación de todo tipo de identidades particulares, territoriales, étnicas y sociales, que se limitan a coexistir en un Estado plurinacional y multicultural, diluye todos los factores de unión: la nación y, con ella, la continuidad de la constitución de la comunidad política, la ciudadanía como sujeto de los derechos políticos, y las instituciones históricas y representativas que simbolizan y expresan la integración de la comunidad política: el Parlamento y la Corona en las monarquías parlamentarias. Sin nación común como sustrato, la constitución queda como mera norma que organiza y distribuye el poder, dejando los derechos como posiciones de poder y como expresión de anhelos subjetivos y aspiraciones de grupos. En definitiva, una constitución funcional, desencarnada y, por ello, frágil y vulnerable. De hecho, se tiende a separar la democracia del constitucionalismo con los valores que lo sustentan: el Estado de Derecho, la limitación del poder y de las mayorías, y de la nación en la que los anteriores valores y principios arraigan y se ejercen.

La misma noción de constitución de consenso, presente al menos desde Weimar, se pone en crisis y se cuestionan algunos de los compromisos fundamentales del pacto constitucional y la misma idea de pacto, al cuestionarse las renuncias 
efectuadas por las diferentes partes en aras del bien común. No hay que confundir esta defensa de lo particular, que divide, y que culmina con la eclosión de un supuesto derecho a decidir de las partes autoconvertidas en todo, con el pluralismo social y político, sobre el que se asientan las democracias contemporáneas y a partir del cual se forja el consenso constituyente y los demás compromisos fundamentales para la comunidad política. Es más, este identitarismo particularista socava y niega el pluralismo mismo y lo que este implica: la posibilidad de pensar y creer de manera distinta, o de que se proteja la pluralidad al interior de cada comunidad política, imaginada como un todo uniforme. Ya Madison nos advirtió del peligro del espíritu de facción, más pernicioso cuanto más pequeña fuese la comunidad, en la naciente república federal americana. Se impone en cada vez más amplios sectores políticos y de opinión una concepción de la democracia como democracia militante, que sustituye a la democracia pluralista, constitucionalmente establecida en el caso español.

Asistimos a una nueva ruptura respecto de lo que ha supuesto el constitucionalismo liberal-democrático, que hoy nos llega de la mano de diversos populismos, los cuales reivindican la lucha amigo-enemigo como motor de la acción política. Hacen bandera de lo que divide a la comunidad política y cuestionan el pacto constituyente, desconfían de las instituciones de mediación, comenzando por el Parlamento y de la relación representativa que está en su base, así como de los poderes de control, particularmente el judicial y el Tribunal Constitucional. Todo ello en nombre de la afirmación de un principio democrático sin límites ni contrapesos, pero a la vez reducido a la regla de la mayoría.

\section{ALBERTO LÓPEZ BASAGUREN}

Creo que, especialmente a partir de la incorporación de la idea de soberanía popular en los sistemas democráticos contemporáneos, la Constitución no debe vincularse con el concepto de nación; la idea de 'nación' no es ni debe ser el fundamento del Estado ni la referencia a la titularidad de la soberanía. La nación ha quedado, en este sentido, arrumbada de los textos constitucionales hace ya mucho tiempo. Mantener la referencia a ese concepto está ya desfasado, por anticuada y, por lo tanto, por ser fuente de confusión y de problemas. Ningún texto constitucional de nuestro entorno mantiene esa idea de nación; todas se refieren al pueblo, por una parte, y al Estado (por referencia a la 'República' o al país respectivo).

Por otra parte, el surgimiento de la reclamación de la condición de 'nación' por comunidades o pueblos integrados en un Estado con el que no se sienten identificados en ese sentido o en esa condición con la mayoría, provocando un conflicto de identidades nacionales dentro de un mismo país, plantea problemas añadidos en relación con el uso de esa referencia a la 'nación' como fundamento del Estado o titular de la soberanía. Un elemento más reciente que abona la necesidad de desconectarlo de las Constituciones. 
Además del carácter arcaico, anticuado, desfasado, de situar la 'nación' en la base de la Constitución, el concepto de nación es, entre otras por las razones señaladas más arriba, un concepto sobre cuyo significado no hay consenso, con significados multivalentes, por lo que es fuente de confusión o, peor, de malentendidos en un terreno tan trascendental como el del fundamento del sistema político que articula la Constitución.

Es evidente que el término 'nación' se sigue utilizando de forma amplia, especialmente en el ámbito del discurso político. Pero con sentidos diferentes entre sí. Se habla de 'nación' como conjunto de un país, de las personas que integran esa comunidad. En las Constituciones que ya no hacen referencia a la nación en aquel sentido de los liberales revolucionarios franceses siguen quedando residuos de esa acepción, como cuando se habla, por ejemplo, de la bandera o el himno 'nacional'. La Constitución francesa es la única que sigue manteniendo la referencia a la 'soberanía nacional' cuya titularidad atribuye al pueblo francés; pero ni tan siquiera en ella se habla de 'nación' en el sentido de 'pueblo', como elemento básico del Estado.

Pero, en diferentes países, se habla también de nación en referencia a partes de esa misma comunidad, cuando tienen características singulares que las diferencian de las de la mayoría. Hay países en los que esa terminología, en el discurso político, está aceptada con mayor o menor extensión y normalidad, según los casos. Y países en los que las utilizan, sobre todo, partidos nacionalistas de comunidades singulares dentro del Estado, pero cuya utilización es poco menos que un tabú político en el discurso político mayoritario. Este es el caso de España.

Cada vez es más común, sin embargo, que ni tan siquiera entre quienes integran una comunidad con conciencia de identidad 'nacional', sus rasgos sean totalmente distintos de los de la comunidad de referencia frente a la que se define su singularidad. El entrecruce de características, la simultánea pertenencia, el 'mestizaje', la libertad del sentimiento de pertenencia, la disociabilidad entre pertenencia a una comunidad y sentimiento de ajenidad respecto a la otra comunidad, etc., hacen necesario disociar la idea de nación, por una parte, de un significado unívoco, y, por otra, de su significado político más fuerte, como fundamento de la soberanía.

Esa es, precisamente, la vía por la que se ha orientado la experiencia europea, tratando de eludir, por una parte, los efectos nocivos de una concepción homogeneizadora de la identidad nacional de los Estados y, por otra, los de la pretensión de que toda comunidad social que tenga un sentimiento nacional diferenciado pueda considerarse legitimada para ser titular de la soberanía y, en consecuencia, crear su propio Estado 'nacional'. En esta dirección, ha sido importante el trabajo del Consejo de Europa ( $\mathrm{CoE}$ ), que se recogió, como resultado de una profunda reflexión, en el Informe titulado The concept of 'nation', de la Asamblea Parlamentaria del $\mathrm{CoE}$, de 13 de diciembre de 2005 (doc. 10762), dirigido, sobre todo, a afrontar la cuestión de las 'minorías nacionales' y sus derechos en la Europa del siglo Xxi. En ese informe se parte de la constatación de la dificultad, por no 
hablar de la imposibilidad, de llegar a una definición comúnmente aceptada del concepto de nación. Una reflexión que se encuadra en las iniciativas del $\mathrm{CoE}$ sobre esta cuestión, entre las que destaca el Convenio-marco de protección de las minorías nacionales (1995; entrada en vigor en 1998).

Considero que este es el marco en el que hay que situar el uso del término nación, asumiendo que es multívoco en su significado; que, por tanto, no siempre quiere decir lo mismo; y que sus diferentes usos o significados pueden convivir pacíficamente. Fundamentalmente, en este sentido, es compatible la consideración de una nación 'cívica', que identifica al conjunto del pueblo que es base y fundamento del Estado, con una nación 'cultural', que responde a unas características diferenciadas que, en la mayor parte de los casos, es lingüístico-cultural, pero que puede responder a otros criterios. Una consideración que no está exenta de consecuencias 'políticas', como se trató de plasmar en la Resolution 361 (2013) Regions and territories with special status in Europe, de la Chamber of Regions del Congress of Local and Regional Authorities [CPR(25)FINAL, de 30 de octubre de 2013]. Unas consecuencias políticas que se desvinculan totalmente de la titularidad de la soberanía, del derecho a constituir su propio Estado y que se orientan hacia el reconocimiento de una autonomía política dentro del Estado en el que están integradas.

La consecuencia de todo esto, por una parte, es que se reafirma la desvinculación, en el sentido tradicional, entre nación y Constitución. Por otra, que obliga a naturalizar el uso multívoco del término nación y a superar el tabú sobre su uso en relación con comunidades o pueblos que forman parte del conjunto del pueblo que está en la base del Estado y que es titular de la soberanía en su seno.

Pero, finalmente, hay que asumir que esa utilización por comunidades que tienen un sentimiento nacional propio debe quedar desligada de la afirmación de que ello supone su titularidad de la soberanía y, en consecuencia, del derecho a la autodeterminación, en el sentido de los convenios internacionales de derechos, o, en definitiva, el derecho a constituir su propio Estado, tal y como, por el contrario, expresó $\mathrm{CiU}$ en su programa electoral para las elecciones al Parlamento de Cataluña de 2012 y han seguido sosteniendo las fuerzas independentistas catalanas desde entonces.

Por el contrario, la superación del tabú que se plantea en estas líneas es la que expresa Joseph Weiler en su incursión en el debate sobre esta cuestión entre Hèctor López Bofill y Antonio Bar [en I.CON (2019), vol. 17, n. $\left.{ }^{\circ} 4\right)$ ] y es coincidente con el uso en el lenguaje político que se da en el Reino Unido y en Canadá, por poner los dos ejemplos más significativos, al referirse a algunas de las comunidades que integran el país.

\section{ESTHER SEIJAS VILLADANGOS}

La relación actual entre Constitución y nación es tributaria de la acepción jurídica de la misma, que hemos analizado. La Constitución es la expresión de la 
voluntad de la nación, entendida como pueblo y como Estado, sujeto titular de la soberanía.

No obstante, la relación entre Constitución y nación está en la realidad preñada de malentendidos, amparados ficticiamente en una "polisemia por completo irrelevante en el contexto jurídico constitucional» (STC 31/2010, FJ12), referida al término nación. En consecuencia, esta relación la podemos plantear en forma dialéctica, en esta respuesta, desde una teoría general, para reproducir la misma argumentación en la pregunta siguiente, pero desde un patrón particular, referido a la Constitución española de 1978.

Tesis-legalidad: La nación es el pueblo de un Estado titular de la soberanía. Esa soberanía es la potestad originaria para crear derecho, para crear normas que busquen la convivencia, dentro de un marco estable, que provea de seguridad, para la protección de los derechos y libertades de los ciudadanos y para la articulación y garantía del funcionamiento de las instituciones. La nación es la sustancia humana del Estado (Carré de Malberg).

Antítesis-legitimidad: La utilización de otras acepciones de nación, socioculturales, étnicas, lingüísticas, referidas a comunidades imaginarias (Anderson), a cuya forja han contribuido de modo decisivo la obra de historiadores o literatos, aviva polémicas que cuestionan esa, a priori, pacífica y racional concepción de la nación, asimilable a pueblo y a Estado, y cuya regulación democrática se plasma en una Constitución. En ese sentido, se concibe a la nación como un ente político, una comunidad, que predataría al Estado, como un todo y a sus elementos, especialmente al pueblo, colectivamente y a los ciudadanos, individualmente. Estas naciones culturales no han adoptado una estructura estatal, porque no son titulares de la soberanía, además de por no definir objetivamente sus límites, imprescindibles para hablar de Estado, porque se sustentan en vínculos, manifestados subjetivamente, de pertenencia o identidad. También son incompatibles con una constitucionalización de sus presupuestos, porque ello implicaría respetar la libertad y los derechos de todos los ciudadanos, algo que choca con su concepción excluyente, en búsqueda de una homogeneidad que siempre será ilusoria e inviable. Las naciones culturales no son ajenas a las normas fundamentales, pueden tener un reflejo en las constituciones, en cuanto se proteja su existencia y se promueva su riqueza vital.

Un planteamiento hipostático llevaría a albergar la convicción de que un derecho de autodeterminación va aparejado a la idea de nación cultural. En consecuencia, allí donde haya esos trazos de identidad cultural, lingüística o tradicional, ha de haber un Estado. Esto es alterar los fundamentos de la nación cultural, atribuyendo su configuración a otra realidad, con la que comparte únicamente significante, que es la nación jurídico-constitucional, el pueblo, el Estado. Ese componente emotivo que conllevan las naciones culturales, las hace ser pasto especialmente apetecible para el cultivo de propuestas totalitarias y, en la actualidad más frecuentes, populistas.

Síntesis. Un Estado, una nación, un pueblo no excluye, porque así lo preceptúa su norma democrática creadora, que en su seno se forjen naciones 
culturales, a las que ha de proteger, preservar y conciliar con los derechos e instituciones de todos los ciudadanos. Estas naciones culturales pueden ser longevas, o pueden crearse ex novo, no hay límites, más allá del respeto a los derechos de todos y a lo preceptivo de canalizar sus peticiones y propuestas por los procedimientos diseñados por la nación, por el pueblo, por el Estado para todos.

3. En el caso de España, y a diferencia de los textos constitucionales de la posguerra europea, nuestra constitución se refiere a la nación en el preámbulo, además de bacerlo también en el art. 2 ¿Cómo cree que deben interpretarse estas referencias? ¿Qué significado jurídico constitucional cabe atribuirles?

\section{BENITO ALÁEZ CORRAL}

La Constitución española de 1978 utiliza en su Preámbulo y articulado dos conceptos hermanados pero también históricamente contrapuestos en Europa continental (no así en los EEUU), los de nación y pueblo, siguiendo dos tradiciones filosófico-políticas. En mi opinión, el concepto de nación que se utiliza en el Preámbulo y en el art. 2 CE no se refiere, en contra de lo que en ocasiones se sostiene, a un concepto étnico-cultural y prejurídico de nación española, puesto que en tal caso se daría una contradicción en la titularidad de la soberanía entre lo previsto por el Preámbulo — que proclama la soberanía de la nación («en uso de su soberanía») — y lo previsto por el art. 1.2 CE — que residencia en el pueblo la soberanía nacional-.

Esta contraposición entre nación y pueblo tampoco se puede explicar a partir de la tradicional distinción filosófico-política revolucionaria entre soberanía nacional y soberanía popular, dado el carácter democrático con el que la Constitución ha caracterizado a España como Estado (art. 1.1 CE). Más bien hay que ver su explicación, dando congruencia al uso de los dos términos por el texto constitucional, en la paradigmática fórmula usada por el art. 1.2 ( «la soberanía nacional reside en el pueblo español»), al estilo y manera de la prevista en el art. 3 de la vigente constitución francesa de 1958. Trata de conciliar que a un tiempo la soberanía corresponda a un sujeto colectivo que la ejerza en términos igualitarios por el mayor número posible de sus integrantes en cada momento histórico (pueblo español), con que dicho sujeto colectivo se conciba en términos unitarios (nación española), y no como la suma o agregado de diversos pueblos o nacionalidades españolas. De ahí la mención a la nación española en el Preámbulo y en el art. $2 \mathrm{CE}$, como esa versión unificada política y jurídicamente de su sustrato cívico, el pueblo español. Una unidad que se declara indisoluble, a pesar de que se reconozca el derecho a la autonomía de las nacionalidades y regiones (art. 2 $\mathrm{CE}$ ), mientras el pueblo español mismo no la disuelva mediante la reforma constitucional del art. 2 CE. 


\section{PALOMA BIGLINO CAMPOS}

La recepción en la Constitución de la palabra nación es una buena muestra de las dificultades que esta noción plantea en los ordenamientos jurídicos democráticos, sobre todo si estos están dotados, como el nuestro, de un marcado pluralismo territorial.

Antes que nada, conviene señalar que la palabra nación no aparecía recogida en el anteproyecto de Constitución elaborado por la Ponencia constitucional. En efecto, el art. 1.2 de dicho texto, publicado por el Boletín Oficial de las Cortes de 5 de enero de 1977, seguía el modelo establecido por la Constitución de la segunda república y atribuía la soberanía exclusivamente al pueblo. Además, el art. 2 afirmaba que «La Constitución se fundamenta en la unidad de España y la solidaridad entre sus pueblos y reconoce el derecho a la autonomía de las nacionalidades y regiones que la integran».

En el posterior debate, el asunto más polémico fue la introducción, en este último precepto, de la mención a nacionalidades y regiones. Según las actas de la ponencia constitucional, esta redacción era la que había propuesto la minoría vasco-catalana en un texto conciliatorio presentado en la sesión celebrada el 25 de agosto y que sirvió como posterior documento de trabajo.

Durante la discusión del proyecto en la Comisión constitucional, la mención a las nacionalidades motivó el rechazo de algunas fuerzas políticas, como era el caso de Alianza Popular. Para reforzar la unidad y contrarrestar una visión plurinacional de nuestra organización territorial se incluyó, pues, la referencia a la indisoluble unidad de la nación española. (El País, 13 de mayo 1978). En definitiva, para desactivar posibles reivindicaciones de fuerzas nacionalistas, se optó por adoptar su propio lenguaje, lo que llevó a asumir su aparato conceptual.

Fue así como las palabras nación y nacionalidades llegan a la Constitución y marcaron su redacción definitiva. Es evidente que algunos de los problemas que estos términos suscitan se podrían haber evitado si, al igual que ocurre en casi toda Europa, nuestros textos jurídicos hubieran utilizado solamente la noción de pueblo porque nada excluye que, además del pueblo de España, existan otros que atribuyan a sus ciudadanos un estatuto de ciudadanía que complete al anterior.

Esto no supone que deba erradicarse la palabra nación de nuestro lenguaje. Es posible, en efecto, reconocer que existe una nación española, esto es, una comunidad a la que la historia, la lengua y la cultura atribuyen elementos de unidad. También es posible reconocer que, junto a ella, existen otras naciones que aglutinan a los habitantes de otras zonas de nuestro territorio. Ahora bien, sería aconsejable no concebir a estos grupos como naciones en sentido jurídico-político, sino en sentido sociológico. Para evitar conflictos entre naciones, lo mejor es reconocer que todas estas naciones son realidades preexistentes al mundo del Derecho, que sólo debería utilizar la idea de pueblo o de pueblos, en el sentido que se ha expuesto en la respuesta anterior. 


\section{ROBERTO BLANCO VALDÉS}

Para entender esa doble inclusión es imprescindible a mi juico tener en cuenta la coyuntura política en que se elabora la Constitución española, muy influida en todo lo relativo a la organización territorial del Estado por una clara voluntad de satisfacer las reivindicaciones de los nacionalismos, en la esperanza de que ello cerraría un problema histórico —el problema regional, luego nacional y hoy territorial - de una vez por todas. La historia pronto iba a demostrar hasta qué punto aquella voluntad era la expresión de la buena fe y, también, visto en perspectiva histórica, de la ingenuidad de los partidos no nacionalistas, la otra cara de la moneda de la doblez y falta de lealtad de lo que entonces se denominaban nacionalismos periféricos

Recordar en ese sentido el proceso de debate del artículo $2 .^{\circ}$ resulta a mi juico muy pertinente para entender cómo apareció el término nación en nuestra ley fundamental. Y ello porque, sorprendentemente, la primera redacción del que acabaría siendo el precepto más conflictivo de la Constitución -la del Anteproyecto redactado por la ponencia constitucional - no hacía referencia a la nación española y sí a las nacionalidades, concepto este último que fue incluido en el artículo $2 .^{\circ}$ a petición del representaba del nacionalismo catalán en la ponencia, Miquel Roca, quien contó de inmediato con el apoyo de los ponentes socialista y comunista: Gregorio Peces-Barba y Jordi Solé Tura. El texto del Anteproyecto pasaba así a disponer que «la Constitución se fundamenta en la unidad de España y la solidaridad entre sus pueblos y reconoce el derecho a la autonomía de las nacionalidades y regiones que la integran». La llamativa ausencia, por contraste, del término nación para referirse a España se encontraba también el apartado segundo del artículo 1. ${ }^{\circ}$ del Anteproyecto, según el cual «los poderes de todos los órganos del Estado emanan del pueblo español, en el que reside la soberanía». La evidente generosidad política de los partidos nacionales en su voluntad de llegar a un texto de consenso no pudo evitar, sin embargo, que los nacionalistas vascos y catalanes plantearan luego, en el trámite de enmiendas al Anteproyecto, varias que, referidas a los artículos $2 .^{\circ}$ y $1 .^{\circ} .2$ iban dirigidas al reconocimiento de España «como un conjunto de naciones o pueblos unidos por un vínculo confederal»: entre ellas, las que solicitaban sustituir el término España por Estado español, que estaría constituido por «una comunidad de pueblos»; o la que proponía declarar que «la soberanía residía en los pueblos del Estado». La izquierda nacionalista vasca añadía, además, otras enmiendas que tenían por objeto que la Constitución reconociera la plurinacionalidad del Estado y el derecho de autodeterminación de sus pueblos.

En este contexto —el del reconocimiento constitucional de que en España existían nacionalidades y regiones pero no una nación mencionado como tal en el texto constitucional - se produjo un duro tira y afloja parlamentario entre el entonces denominado nacionalismo moderado (PNV y Convergencia Democrática de Catalunya), la izquierda nacional (PSOE y PCE), la extrema izquierda 
nacionalista (ERC y EE) y los partidos mayoritario y minoritario de la derecha nacional (UCD y AP), derechas que estaban en esa materia abiertamente enfrentadas, dada la negativa radical de AP a aceptar que la palabra nacionalidades figurase en la ley fundamental. Como consecuencia de ese debate parlamentario y de los pactos que permitieron alumbrar la Constitución, el término nación, referido a España, se recogió finalmente en la redacción definitiva de los dos artículos citados, al mismo tiempo, que se mantenía el de nacionalidades, pese al referido rechazo frontal de uno de los partidos nacionales, Alianza Popular, que fraguaron el consenso de 1978. Aunque el texto definitivo del artículo 1.2 («La soberanía nacional reside en el pueblo español, del que emanan los poderes del Estado») quedó ya fijado en el documento de la ponencia, el del artículo 2 tuvo que esperar hasta que en la Comisión Constitucional del Congreso, y tras diversos intentos de modificación de su redacción inicial, fuera aceptada la propuesta de consenso de UCD, que pasó al texto de la ley fundamental: «La Constitución se fundamenta en la indisoluble unidad de la Nación española, patria común e indivisible de todos los españoles, y reconoce y garantiza el derecho a la autonomía de las nacionalidades y regiones que la integran y la solidaridad entre todas ellas».

A la vista de lo que acaba de apuntarse, parece obvio, pues, que el término nación entra en la Constitución para referirse a España en su conjunto y, sobre todo, para subrayar su carácter nacional junto al reconocimiento de la existencia de nacionalidades y regiones. Para expresarlo con mayor claridad: en España no hay jurídicamente más nación que la española, pues el término nacionalidades no es en absoluto equivalente al de nación, de ahí la clara distinción entre uno y otro establecida por el constituyente. Por tanto, ninguno de los territorios que forman parte de la nación española son naciones, sino nacionalidades o regiones, con el sentido que de inmediato trataré de explicar. Y por tanto ninguna puede pretender el reconocimiento en el plano internacional de los derechos que se conceden a las llamadas naciones sin Estado en el contexto de situaciones de dominio colonial o de ausencia de un sistema que reconozca los derechos y libertades (Resoluciones de Naciones Unidas 1514 y 1541 de 1960, 1654 de 1961 y 2625 de 1970) situaciones ambas que no se corresponden en absoluto con la realidad española.

\section{JOSEP M. ${ }^{a}$ CASTELLÁ ANDREU}

La Constitución de 1978 asume la existencia previa tanto de la Nación como de las nacionalidades y regiones: contiene una referencia a la Nación española como fundamento de la Constitución — «la Constitución se fundamenta en la indisoluble unidad de la Nación española»—, para, a continuación, afirmar la naturaleza plural de dicha Nación, al añadir que «reconoce y garantiza el derecho a la autonomía de las nacionalidades y regiones» (art. 2), además de enunciar la forma de Estado — «España se constituye en un Estado social y democrático de Derecho» (art. 1.1) — Ello a diferencia de la Constitución de 1931, la cual solo 
alude a España como república democrática (art. 1), al Estado español, y consagra el Estado integral como forma de Estado, compuesto por las regiones autónomas que se constituyan.

En el informe de la Ponencia se incorporó la referencia a la Nación española, a partir de una enmienda de J.M. García-Margallo (UCD), de modo que se equilibraba la referencia a las nacionalidades y regiones, presente desde el primer borrador. Ello era coherente con lo que los gobiernos de la Transición tuvieron presente desde casi el inicio, y de lo que da cuenta Landelino Lavilla en sus memorias (2017): ya la Exposición de motivos del Real Decreto Ley 10/1976, de 30 de julio, sobre amnistía, comenzaba señalando «la Corona simboliza la voluntad de vivir juntos todos los pueblos e individuos que integran la indisoluble comunidad política española».

No estamos, pues, como recordaba Rubio Llorente (2012), ante un Estado plurinacional, o un Estado de nacionalidades (y regiones), sino ante una Nación de nacionalidades y regiones, que fundamenta la Constitución, y, por ello, le da vida y sustancia de comunidad política, sin quedar en mero agregado o yuxtaposición de sujetos políticos soberanos. Desde el Preámbulo está claro, al proclamar a la nación española como sujeto soberano y, por tanto, constituyente, que ejerce el pueblo español como un todo (art. 1.2), sin perjuicio de que esta nación esté formada por «los pueblos de España», en plural. De este modo, nación española, constitución y ciudadanía común aparecen vinculados.

Hoy nos hallamos ante algunas propuestas de reforma o, más bien, de cambio constitucional que quieren romper con este vínculo, atribuyendo el carácter de nación a las nacionalidades y eliminando el de nación española para consagrar un Estado plurinacional. O, ante la imposibilidad de llevar a cabo esta reforma, algunos sectores políticos proponen interpretar el Estado autonómico como un Estado plurinacional o una entidad de carácter confederal. Ello conlleva sustituir el pueblo español como poder constituyente por un pacto entre entidades territoriales autoproclamadas soberanas. De este modo, se pone en crisis la constitución de consenso, como gran acuerdo entre ideologías y grupos distintos, y el modelo de comunidad política que asume la Constitución, plural e integrado a la vez por lazos de solidaridad (art. 2), tal y como ha concretado el Tribunal Constitucional desde el inicio (de forma meridiana en la sentencia 76/1988: «la Constitución no es el resultado de un pacto entre instancias territoriales históricas»).

\section{ALBERTO LÓPEZ BASAGUREN}

Es la única Constitución de nuestro entorno que se refiere a la nación en esos términos, lo que, sin duda, resulta llamativo y, creo, es significativo de un estado de sensibilidad política peculiar en el momento de elaboración del texto constitucional. Creo que la insistencia asfixiante sobre la nación española durante el 
régimen franquista y la influencia de nuestro constitucionalismo histórico, fuertemente condicionado por aquella primitiva tradición francesa, acabaron condicionando una opción que ya estaba absolutamente desfasada a la luz de las Constituciones de nuestro entorno. Muchas Constituciones se refieren a la indivisibilidad del Estado, pero ninguna lo hacen en los términos del art. 2 de nuestra Constitución y, aún menos, en referencia a la 'Nación'.

En cualquier caso, esa referencia está en el texto constitucional y, por tanto, debe precisarse qué significado jurídico tiene. Por una parte, el Preámbulo se refiere a la Nación española como titular de la soberanía; pero se refiere, igualmente, a 'los pueblos de España' y a sus tradiciones y culturas, lenguas e instituciones. Significa que, a pesar de la terminología en torno a la 'Nación española', la visión de la Constitución sobre esa 'Nación' es pluralista, con la mayor amplitud. La afirmación sobre la titularidad de la soberanía en el art. 1, sin duda, hay que interpretarla en el sentido de soberanía popular, sin ningún residuo de una concepción arcaica relativa a la 'soberanía nacional'. La reiterativa referencia del art. 2 a la indisolubilidad de la 'Nación española' solo puede ser interpretada en el sentido de indivisibilidad del Estado y consiguiente inexistencia de cualquier otra titularidad de la soberanía que no sea la del pueblo español, en su conjunto. Es decir, más allá de las palabras utilizadas, la Constitución se sitúa plenamente, sin resquicio alguno, en el ámbito de las Constituciones democráticas contemporáneas que se asientan sobre el principio de soberanía popular cuyo titular es el pueblo que está en la base del Estado; como no podía ser de otra forma. En este sentido, la Constitución utiliza el término Nación en el sentido de pueblo o de Estado, según los casos.

En mi opinión, por tanto, sobre la base del uso del término Nación en la Constitución no cabe articular una construcción jurídico-constitucional distinta de la de los sistemas constitucionales de nuestro entorno en el sentido de soberanía popular, por una parte, e indivisibilidad del Estado, por otra; una y otra, características presentes, de forma expresa o tácita, en las Constituciones de todos los países de nuestro ámbito jurídico-político.

\section{ESTHER SEIJAS VILLADANGOS}

Enlazando con la anterior respuesta, la referencia de la Constitución de 1978 al término Nación tiene una clara adscripción a la acepción jurídica que, consecuentemente, se denomina jurídico-constitucional y que se sintetiza en la consideración del pueblo como titular de la soberanía. Siguiendo el mismo esquema dialéctico, plantearemos un silogismo para su explicación.

Tesis: el pueblo español como nación constituyente y como soberano, una cuestión desde la legalidad. La apuesta del modelo revolucionario francés por la acepción jurídica del término nación y por su constitucionalización recaló tempranamente en nuestro constitucionalismo de la mano de la Constitución de 
1812. Tres artículos son emblemáticos de esa regulación de Nación: El artículo 1 , «La nación española es la reunión de todos los españoles de ambos hemisferios»; el art. 2, «La Nación española es libre e independiente, y no es ni puede ser patrimonio de ninguna familia o persona»; el art. 3 donde se vincula nación a soberanía y, por consiguiente, a Estado. «La soberanía reside esencialmente en la Nación y, por lo mismo, pertenece a esta exclusivamente el derecho de establecer sus leyes fundamentales» y el art. 4, donde se conecta Nación a Estado de Derecho, mediante el mandato constitucional de acudir a «leyes sabias y justas» para proteger los derechos de los individuos. Es relevante cómo en este bautismo constitucional se afianzó con meridiana claridad lo que nuestra Constitución vigente contempla, aunque de modo menos expreso y expresivo. La nación española somos todos los españoles, ahora ya en un solo hemisferio. La nación no es susceptible de patrimonialización, ni de homogeneización cultural impuesta, porque la nación respeta e integra esa pluralidad al afianzar los derechos de los ciudadanos. Finalmente, la principal potestad de la nación es aprobar las normas por las que ha de regirse y que ha de respetar y que, también, está facultado para cambiar, cuando tenga los apoyos de las mayorías que procedimentalmente exija la Constitución. Las vicisitudes de la recepción de la nación en nuestro constitucionalismo han pasado por su inclusión en las constituciones progresistas, como 1869, y su ausencia de las doctrinarias, como 1876. En la Constitución de 1931 no aparece el término nación, pero sí España y Estado español, y no se duda en identificar el primero de sus títulos como «Organización nacional», al hablar de municipios, provincias y regiones autónomas.

La Constitución española de 1978 inicia su redacción con la palabra la Nación española, ubicada en el preámbulo, donde también se hacen presentes las expresiones pueblos de España y pueblo español. El significado y el sentir de esa referencia a Nación es la expresión de un desiderátum firme que se desgrana a lo largo de esa relación de infinitivos que todos conocemos: garantizar, consolidar, proteger, promover, establecer, colaborar. Como el Tribunal Constitucional señaló tempranamente, el valor jurídico de los preámbulos se agota en su cualificada condición como criterio hermenéutico «elemento a tener en cuenta en la interpretación de las leyes», no normativo (STC 36/1981, FJ 7). Sin embargo, esa carencia de valor normativo no es equivalente a «carencia de valor jurídico» (STC 31/2010, FJ 7). En consecuencia, se afianza la categorización de Nación como término jurídico-constitucional, con el significado que hemos reiterado de conjunto de ciudadanos iguales en derecho que se constituyen en Estado, acto formalizado mediante la proclamación de una Constitución, sobre la cual plasman su voluntad y compromiso de realizar todos los objetivos marcados en el preámbulo. En el artículo de apertura, donde se define la «fórmula política» de la Constitución y del Estado al que regula (Lucas Verdú), se utiliza la expresión nación en forma adjetivada, vinculada al sustantivo soberanía, que deviene así en «soberanía nacional». No deja de ser un pleonasmo, porque la soberanía en un Estado democrático lo es de toda la Nación, esto es de todos los ciudadanos que configuran ese Estado. 
Cabe trazar unos matices entre el pueblo español al que se alude en el preámbulo y cuyo cometido se explicita justo al final del mismo, la ratificación de la Constitución, y el que se referencia en el art. 1.2 como titular de la soberanía nacional. En el preámbulo se alude a la nación constituyente, a los ciudadanos españoles que tuvieron derecho a participar en las primeras elecciones democráticas de junio de 1977, que configurarían las instituciones legislativas, Congreso de los Diputados y Senado, que aprobarían la Constitución que a su vez fue ratificada por los ciudadanos, por la Nación española en diciembre de 1978. Por su parte, el titular de la soberanía nacional que referencia el art. 1.2 CE no puede concretarse de modo tan preciso, haciendo alusión a un colectivo indeterminado, al que corresponde su status de nación constituida, no susceptible de ser fraccionado - de conformidad con los atributos que le asignan en el art. 2 «indisoluble unidad»—, que tiene la función de implementar esa voluntad marcada en el preámbulo constitucional, a través del respeto y guarda de los derechos de todos y de su compromiso con la configuración y funcionamiento de las instituciones y que, llegado el momento, puede acometer un proceso de reforma constitucional siguiendo los procedimientos marcados en la Constitución. El término jurídico de nación que aparece en el artículo 2 es la referencia a Estado, a España, y el reconocimiento de su principal atributo que es la unidad. Una unidad que no puede asimilarse a unitario. La unidad estatal es inherente al Estado, fue el logro de la gestación renacentista del mismo (Maquiavelo), frente a las poliarquías medievales. Todos los estados contemporáneos son fundados en torno a la unidad, sin que ello sea incompatible con dotarle de fórmulas descentralizadas para la gestión de sus intereses y para la atribución de poderes y competencias a otras unidades territoriales que se habilitan dentro del mismo y que son compatibles con esa unidad.

Antítesis: la patrimonialización de la nación, una reivindicación desde la tergiversación de la legitimidad. Es importante como en el momento presente se percibe una marcada tendencia a tensionar la acepción de Nación que hemos visto en la Constitución. Simplificando los impulsores de dicha tendencia, podemos identificar los liderazgos populistas que tratan de apoderase de la nación y los que afloran desde la acepción socio-cultural de nación, que aspiran a hipostasiarla en jurídica, reivindicando su conversión en Estado. El siglo XXI ha arrancado con el protagonismo de quienes claman por unas personalizaciones populistas de la nación, «el pueblo soy yo» (Krauze). Sin ningún pudor tratan de subvertir todo el proceso de consolidación y democratización que ha catapultado a las naciones contemporáneas, en particular la española, a las mayores cotas de libertad, seguridad y respeto a los derechos de los ciudadanos, de todos los ciudadanos, argumentando que su liderazgo puede subsumir todas las instituciones y todos los poderes, a los efectos de convertirse en la personificación más insolente del Estado soy yo. Desde otro frente, el cuestionamiento de la nación viene impulsado por la convicción de que una nación cultural tiene aparejado un derecho, sin ser una categoría jurídica, a convertirse en Estado. Para ello, no se duda en tomar buena cuenta de las demagogias populistas aludidas, que se acotan espacialmente 
y que se reivindican como los legítimos, verdaderos, únicos, exclusivos y excluyentes representantes de esa comunidad que nadie duda puede compartir lengua, tradición, derechos y aspiraciones, y que se empeña en convertir cada día y cada acto en «un plebiscito», el plebiscito de todos los días (Renan). El denominador común entre estos dos aspectos es la polarización de la sociedad, de los ciudadanos, de la Nación. Cada uno tirando por un lado de una cuerda, cuya fortaleza radica en la consideración de que todos nosotros somos no solo su funda o camisa, sino su núcleo o su alma.

Síntesis: la conciliación de legalidad y legitimidad de la nación. La conceptualización de la nación como una categoría jurídico-constitucional no merma, en absoluto, la legitimidad de la misma, sino que la fortalece, porque le confiere una seguridad y una garantía de que se ha de respetar por todos los actores. En la Constitución, como ha recordado el Tribunal Constitucional, «caben cuantas ideas quieran defenderse sin recurrir a la infracción de los procedimientos. Incluso la defensa de concepciones ideológicas que pretendan para una comunidad determinada la condición de comunidad nacional» (STC 31/2010, FJ 12). Para dar un paso más allá, habrá que atenerse a la Constitución y a lo que los ciudadanos, con su soberanía constituida decidan, decidamos.

4. ¿Qué relevancia cabe atribuir a las contraposiciones conceptuales que establece el art. 2 entre nación española, nacionalidades y regiones?

\section{BENITO ALÁEZ CORRAL}

Partiendo de la afirmación antes expuesta de que tanto la nación/pueblo español como las nacionalidades/pueblos territorialmente ubicados en el Estado español son creaciones — jurídicamente hablando- de la Constitución española de 1978, la diferencia jurídica entre una y otras solo puede ser de competencias o poderes jurídicos, por más que ciertamente esta diferencia competencial refleje o pueda ser entendida también como una diferencia de importancia política. Mientras que el pueblo español del art. 1.2 CE, en tanto que titular de la soberanía nacional, es titular también del poder constituyente-constituido, es decir, del poder de reforma constitucional, y lo ejerce a través de los órganos y con los procedimientos previstos en el Título $\mathrm{X}$, las nacionalidades a que se refiere el art. 2 CE, constituidas en CCAA, y por tanto sus pueblos autonómicos, solo son titulares, una vez constituidas en Comunidades Autónomas conforme a lo previsto en el Título VIII CE, de los poderes constituidos (legislativo y ejecutivo) que hubieran asumido de acuerdo con la CE y sus respectivos Estatutos de Autonomía. Respecto del ejercicio del poder constituyente constituido a través del procedimiento de reforma constitucional, los pueblos autonómicos/nacionalidades únicamente poseen una competencia de iniciativa a través de sus Asambleas Legislativas, conforme a lo dispuesto en los arts. 116 y 87.2 CE. 
Nada de lo anterior prejuzga la importancia o insignificancia política que se quiera atribuir a cada uno de esos conceptos (nación española o nacionalidades), ni tampoco predetermina la justicia o moralidad en términos ético-políticos del estatus atribuido a una y a otras, que es consecuencia de avatares históricos. Ahora bien, en términos jurídico-democráticos, la CE de 1978, garantizando el derecho de participación política de todos los ciudadanos que se integran en el pueblo español y en los pueblos/nacionalidades autonómicos, ha repartido las competencias y poderes de uno y otros en los términos expuestos, y aunque ese reparto no es preconstitucional ni eterno y se puede modificar, solo es alterable en los estrictos términos del Título $\mathrm{X}$, es decir, a través de una reforma constitucional.

Tampoco se dice nada en la CE de la diferencia textual que el art. 2 CE hace entre nacionalidades y regiones. Ciertamente, parece estar implícita en el uso de la distinción misma una diferencia en la conciencia política que como entes puedan tener unas y otras: las nacionalidades se sentirían naciones pero carecerían de soberanía y las regiones no. Sin embargo, en la medida en que el ejercicio del derecho a la autonomía, su única forma de expresión jurídica, de unas y otras se reconduce a través de los procedimientos del Título VIII a la voluntad expresada por los órganos representativos de la ciudadanía y por la ciudadanía misma tanto de nacionalidades como regiones, entiendo que la Constitución ha dejado en manos de la ciudadanía de cada uno de los territorios que aspiran a la autonomía política la autocalificación como nacionalidad o como región, lo que han hecho en sus respectivos Estatutos de autonomía —o en sus modificaciones-, sin perjuicio de su irrelevancia jurídica.

\section{PALOMA BIGLINO CAMPOS}

Antes he hecho referencia a la manera en que las nociones de nación y nacionalidad hicieron su entrada en el texto constitucional. Ahora conviene resaltar que el Tribunal Constitucional, ya en la STC 31/2010, atribuyó a dicho término un sentido que coincide, en gran medida, con la noción que aquí se ha denominado jurídico-política y que dicho órgano califica de jurídico-constitucional. En esa ocasión, el Tribunal excluyó que la nación que recoge nuestra norma fundamental fuese una realidad cultural, histórica, lingüística, sociológica o religiosa. En sentido distinto, afirmó que «la Constitución no conoce otra que la Nación española, con cuya mención arranca su preámbulo, en la que la Constitución se fundamenta (art. 2 CE) y con la que se cualifica expresamente la soberanía que, ejercida por el pueblo español como su único titular reconocido (art. 1.2), se ha manifestado como voluntad constituyente en los preceptos positivos de la Constitución Española» (fj 12). La posterior jurisprudencia del Tribunal Constitucional, dictada para hacer frente a la crisis secesionista comparte la misma visión. Recordemos que la Ley 20/2017, de transitoriedad jurídica y fundacional de la República, dedicaba su art. 2 a la soberanía nacional, que se atribuía al pueblo de 
Cataluña y, en Arán, al pueblo aranés. Frente a ello, la STC 124/2017 negó que el pueblo de Cataluña fuera titular de un poder soberano porque este es «exclusivo de la Nación [española] constituida en Estado».

Las palabras nacionalidades y regiones tienen otra dimensión distinta. De los debates constituyentes se deduce que ambas realidades, aunque recogidas en la Constitución, no tienen la dimensión jurídico-política a la se ha hecho referencia en la primera respuesta a este cuestionario. En efecto, casi todas las intervenciones acerca del tema se refieren a una comunidad, dotada de rasgos peculiares que la identifican frente a las demás. Pero esta realidad, que la Constitución reconoce, las hace merecedoras de autonomía. No son, pues, naciones que puedan reclamar para sí soberanía (SSTC 4/1981, 25/1981).

No es fácil deducir lo que los constituyentes entendían por regiones. Ahora bien, de la realidad de España de aquella época, así como del resto de la norma fundamental, cabe concluir que el término hace referencia a comunidades asentadas en un determinado territorio, dotadas de ciertos elementos comunes de menor intensidad que las nacionalidades. Las regiones, pues, carecen de los hechos diferenciales, sobre todo lingüísticos, que caracterizan a las nacionalidades y que sirven para identificar a determinadas partes de nuestro país con respecto a las otras.

Durante los primeros años de vigencia de la Constitución esta distinción sirvió para justificar la existencia de dos vías de acceso a la autonomía ya que se pensaba que las nacionalidades acudirían a la vía rápida, mientras que las regiones optarían por la vía lenta. Como es sabido, estos distintos procedimientos daban lugar a diferentes regímenes competenciales. Ahora bien, esta distinción careció de efectos prácticos. En efecto, hubo zonas de España sin lengua propia, como Andalucía, que accedieron por la vía rápida al máximo nivel competencial y que, ahora, se definen como nacionalidad en sus propios Estatutos.

Es posible que la distinción entre nacionalidades y regiones tenga significado político para quienes reivindican para las primeras una forma de ser que las distinga de las segundas. También es verdad que nuestro sistema jurídico establece diferencias entre Comunidades Autónomas, en temas como la lengua, policía autonómicas o administración de la administración de justicia. La más notable de ellas es la que existe entre las que son forales y las que no los son. Pero lo cierto es que no es posible anudar dichas diversidades con la distinción que recoge el art. 2 CE.

\section{ROBERTO BLANCO VALDÉS}

La pregunta podría contestarse afirmado sencillamente que ninguna relevancia, según lo ha demostrado con toda claridad el proceso de construcción del Estado autonómico. Pero resistiré la testación de despachar de ese modo una cuestión de la que podría afirmarse lo que en su día manifestó la Corte Suprema de los Estados Unidos respecto del fondo del asunto que se suscitaba en el celebérrimo 
Mandamus Case (Marbury v. Madison): que, felizmente, la cuestión formulada en la pregunta «no es de dificultad proporcional a su interés».

En efecto, y de un modo sorprendente, la batalla política y parlamentaria que se produjo en la Constituyente a cuenta de la redacción del artículo 2 no guardó relación con el impacto — nulo, a fin de cuentas - que iba a tener con posterioridad la inclusión del término nacionalidades en nuestra ley fundamental. Y ello por varias razones que es necesario constatar y que además de dar una idea cabal de la relevancia jurídica del término nacionalidades sirven también para explicar su verdadero significado. Lo primero que debe subrayarse, a mi juicio, es la circunstancia de que el término nacionalidades no vuelva a aparecer en el texto de la Constitución, hecho esencial del que se deriva otro no menos importante: que nuestra ley fundamental no deja, por tanto, constancia ni de cuáles son las nacionalidades españolas ni de qué consecuencias podrían o deberían derivarse, en su caso, del hecho de que un determinado territorio sea jurídicamente considerado como tal. La innegable relevancia de ese silencio fue señalada ya hace años por Francisco Rubio con rotunda claridad: «Cierto que la Constitución hizo posible la existencia de dos niveles distintos de autonomía; cierto, también, que se refiere, aunque sin definirlas, a nacionalidades y regiones como realidades sociológicas diferentes. Pero cierto es, sobre todo, que no hay precepto constitucional alguno que establezca una correlación necesaria y permanente entre esa diferencia sociológica (una diferencia, por lo demás, que no ha sido objeto de teorización y cuya vaguedad permite todo género de juegos interesados), y la diferencia jurídica que implican los distintos niveles de autonomía». Tras un razonamiento del que parece difícil discrepar, concluía el gran constitucionalista español: que «el espíritu de la Constitución lleva a la abolición de toda diferencia porque la equiparación competencial de todas las Comunidades es la solución congruente».

Contra lo que podría derivarse de una lectura aislada del artículo 2, lo cierto es que el proceso descentralizador no se basó en la diferencia que el mismo establecía entre nacionalidades y regiones sino en las previsiones del artículo 143.1, en el que el poder para iniciar el proceso político que ha de conducir a la constitución de un territorio en Comunidad Autónoma no se atribuye a las nacionalidades y regiones sino a las provincias limítrofes con características históricas, culturales y económicas comunes, a los territorios insulares y a las provincias con entidad regional histórica. Serán esos y no otros los sujetos que podrán acceder a su autogobierno y constituirse en Comunidades Autónomas con arreglo a lo previsto en el Título VIII de la Constitución y en los respectivos Estatutos de Autonomía. Es verdad que junto a los mencionados sujetos del artículo 143.1, la disposición transitoria segunda de la Constitución otorga también la iniciativa autonómica a los territorios que en el pasado hubiesen plebiscitado afirmativamente proyectos de Estatuto de autonomía y contasen, al tiempo de promulgarse la Constitución, con regímenes provisionales de autonomía. Con tal perífrasis jurídica pretendía el constituyente privilegiar en el acceso a la autonomía del País Vasco y Cataluña, para dar así una salida rápida y segura a la reivindicación 
descentralizadora de los dos territorios que contaban con fuerzas nacionalistas en las Cortes Constituyentes. Pero la aludida previsión se tradujo a la postre en un mito que muy pronto pasaron a compartir, casi con carácter general, los políticos españoles (de izquierdas y de derechas, nacionalistas y no nacionalistas), gran número de juristas, y la práctica totalidad del mundo periodístico, consenso de facto que dio lugar a su asunción por la mayoría de los españoles que tienen opinión sobre el asunto: que en España había no sólo nacionalidades, según establecía el artículo 2, sino también nacionalidades históricas y que estas no eran otras que las incluidas, a través de la perífrasis citada, en la disposición transitoria segunda de la ley fundamental. No hay que darle muchas vueltas al asunto para constatar la rotunda falsedad de esas dos afirmaciones: ni nuestra ley fundamental se refiere en parte alguna a las nacionalidades históricas, ni, por lo mismo, existe en ella base alguna sobre la que sostener que tales nacionalidades históricas, constitucionalmente inexistentes, serían Cataluña, el País Vasco y Galicia, territorio este último al que también afectó la cita transitoria por haber plebiscitado un Estatuto en 1936. Y ello por más que tan falsa y gratuita presunción se haya generalizado hasta convertirse desde hace mucho en un lugar común de la política española

¿Cabe afirmar, en conclusión, que de la inclusión del término nacionalidades en la Constitución pueden o deben derivarse efectos jurídicos? La respuesta me parece sencilla: la referida distinción, y esta es su única y exclusiva consecuencia, abrió la posibilidad de que las Comunidades Autónomas se definan en sus normas estatuarias como nacionalidades o como regiones según la voluntad de sus respectivos parlamentos, finalmente confirmada o no por las Cortes Generales. La irrefutable prueba de lo que acaba de apuntarse es que la respectiva definición de cada Comunidad como nacionalidad o como región ha ido cambiando con el tiempo, que ha marcado una tendencia general al aumento del número de nacionalidades. Entre los Estatutos redactados tras la entrada en vigor de nuestra ley fundamental sólo cinco — los de Cataluña, el País Vasco, Galicia, Andalucía y Valencia- definieron a sus respectivos territorios como nacionalidades, aunque utilizaran a tal efecto diferentes fórmulas jurídicas. Ya entonces la inclusión en ese grupo de las Comunidades andaluza y valenciana contradecía con toda claridad, desde los mismos momentos iniciales del proceso descentralizador, la presunción de que aquella naturaleza podía atribuirse únicamente a las supuestas nacionalidades históricas de la disposición transitoria segunda de la Constitución: «El Pueblo Vasco o Euskal-Herria, como expresión de su nacionalidad, y para acceder a su autogobierno, se constituye en Comunidad Autónoma dentro del Estado Español bajo la denominación de Euskadi o País Vasco [... . »; «Cataluña, como nacionalidad y para acceder a su autogobierno, se constituye en Comunidad Autónoma [...]»; «Galicia, como nacionalidad histórica, se constituye en Comunidad Autónoma para acceder a su autogobierno»; «Andalucía, como expresión de su identidad histórica, y en el ejercicio del derecho al autogobierno que la Constitución reconoce a toda nacionalidad, se constituye en Comunidad Autónoma [...]»; «El pueblo valenciano, históricamente organizado como Reino de Valencia, se constituye en Comunidad Autónoma, dentro de la indisoluble unidad 
de la nación española, como expresión de su identidad histórica y en el ejercicio del derecho al autogobierno que la Constitución reconoce a toda nacionalidad [...]». Eso disponían en sus títulos preliminares respectivos los cinco Estatutos de las Comunidades previamente mencionadas. En claro contraste con ello, el término nacionalidad no fue recogido por ninguno de las restantes normas estatutarias que se adoptaron hasta que en 1983 se cerró el proceso estatuyente. Pero lo que no aconteció en la fase inicial del proceso descentralizador se produjo con posterioridad, en varios procesos de reforma estatutaria. Y así, a las cinco nacionalidades iniciales vinieran a añadirse otras tres más, en clara demostración de que la dimensión jurídica del término nacionalidad del artículo 2 de la Constitución no era otra que la apuntada: abrir la posibilidad de que el legislador estatuyente optase por definir a su respectivo territorio como nacionalidad y no como región. Lo hicieron de ese modo, mediante procesos de reforma, las normas institucionales básicas de las Comunidades Autónomas de Aragón («Aragón, nacionalidad histórica, ejerce su autogobierno de acuerdo con el presente Estatuto [...]»), Canarias ( Canarias, como expresión de su identidad singular, y en el ejercicio del derecho al autogobierno que la Constitución reconoce a toda nacionalidad, se constituye en Comunidad Autónoma [... ]») y las Islas Baleares («La nacionalidad histórica que forman las islas de Mallorca, de Menorca, de Ibiza y de Formentera, como expresión de su voluntad colectiva y en el ejercicio del derecho al autogobierno que la Constitución reconoce a las nacionalidades y a las regiones, se constituye en Comunidad Autónoma [....]»). La conclusión, pues, no parece ofrecer dudas: frente a quienes siguen empeñados, sin la más mínima apoyatura constitucional, en que en nuestro sistema autonómico hay tres nacionalidades y además históricas (las de la disposición transitoria segunda de la ley fundamental) la pura verdad es que 8 de nuestras 17 Comunidades Autónomas —es decir, casi la mitad - se autoafirman hoy como nacionalidades en sus Estatutos, sin que nadie haya discutido su pleno derecho constitucional a autocalificarse de ese modo, ni nadie ponga en duda que las regiones que no se han calificado hasta la fecha de nacionalidades no puedan hacerlo en el futuro si así lo decidiesen sus respectivos parlamentos y lo apoyasen las Cortes Generales.

\section{JOSEP M. ${ }^{a}$ CASTELLÁ ANDREU}

El art. 2 CE trata de hacer compatibles, como hemos visto, la afirmación de la Nación española — «patria común e indivisible»— con el derecho a la autonomía de nacionalidades y regiones. De este modo, la Constitución adopta una posición, más que de equilibrio entre unidad y diversidad — como suele decirse-, de entendimiento de la unidad como unidad plural y no como uniformidad. Con ello se superaban otros tipos de acercamiento a la realidad de España por parte de nuestro constitucionalismo histórico. No es menor la relevancia de esta innovación constitucional. Se trató de uno de los más difíciles acuerdos de la Transición, del que se advirtieron riesgos e incongruencias semánticas (Fraga, Julián Marías), con el que se 
pusieron los cimientos para la creación del Estado autonómico. En aquel momento, la mención de las nacionalidades consiguió que tradiciones políticas distintas vieran reconocidas sus aspiraciones en el texto constitucional y que el nacionalismo catalán entonces mayoritario participara activamente en el pacto constitucional. A su vez, dichas aportaciones constitucionales enlazaban con referentes ideológicos e históricos bien diversos: el austro-marxismo de Bauer, la noción de «nación de naciones» del socialista Anselmo Carretero, la nacionalidad catalana presente desde Prat de la Riba en el nacionalismo catalán, o las experiencias del Reino Unido o de Austria-Hungría. Solé Tura (1985) afirmó que el art. 2 supone un «empate» entre dos concepciones diferentes de la nación española: la unitaria y como conjunto articulado de pueblos diversos, pero que sienta las bases para la superación del enfrentamiento. No lo supera, pero facilita que se pueda hacer. Esta es una tarea nunca definitivamente acabada, que requiere voluntad permanente de pacto y de concordia políticos.

Pero desde muy pronto el art. 2 fue ignorado en su potencial integrador por unos y por otros para conseguir propósitos que desentonaban con una interpretación auténtica del mismo y con otra sistemática del documento constitucional. Así, se ha tratado de vincular nacionalidad con nación en el sentido jurídico de sujeto de soberanía, o bien de equiparar nacionalidad con régimen especial de acceso a la autonomía (Disposición transitoria II o art. $151 \mathrm{CE}$ ), derivando de ello una lectura «italianizante» de la autonomía o asimétrica en sentido fuerte, con comunidades autónomas con distinto régimen constitucional de autogobierno.

Frente a ello, el Tribunal Constitucional ha enfatizado el carácter limitado y derivado del poder de autogobierno, y que autonomía no equivale a soberanía (sentencias 4/1981 y 42/2014). Por tanto, excluye el derecho a la autodeterminación de las nacionalidades o la atribución de poderes constituyentes. Asimismo, ha sostenido que la nacionalidad puede identificarse con nación cultural, histórica, sociológica o lingüística pero no con nación en sentido jurídico-constitucional (STC 31/2010).

De este modo, se parte de la distinción clásica entre nación jurídica y nación cultural, pero no se presta atención suficiente, a mi juicio, al sentido político o volitivo de nacionalidad, que también tuvo la constitucionalización de las nacionalidades, como subrayaran Herrero y Roca en los debates constituyentes. El límite está claro: la nacionalidad tiene derecho a la autonomía, que concreta el Estatuto, pero no de autodeterminación o poderes soberanos, que corresponden en exclusiva a la nación española. Más difícil es concretar un contenido positivo de la inclusión de las nacionalidades, más allá de ser sujetos que ejercieron en su momento el derecho a la autonomía.

En la lógica constitucional, las nacionalidades y regiones preexisten a la Constitución como entidades territoriales históricas o geográficas, y la Constitución habilita que puedan constituirse en comunidades autónomas, esto es, en entidades jurídico-públicas (art. 137 CE), que cada Estatuto de autonomía funda, las designa con la denominación «que mejor corresponda a su identidad histórica» (art. 147.2 CE), y les ha dotado de un régimen de autogobierno de carácter político y no solo administrativo. 
De este modo, el debate sobre el lugar más idóneo para denominar a las diferentes comunidades autónomas, si la Constitución o el estatuto respectivo, puede conducirse en términos a la vez simbólicos y pragmáticos: los estatutos contienen una «cláusula identitaria» (Solozábal, 2019). Es en ellos donde corresponde mejor introducir la autoidentificación de la comunidad autónoma, esto es, por parte de la norma básica de cada una de ellas, como recomendó el Consejo de Estado en el Informe de 2006 sobre la reforma constitucional. Al mismo tiempo, el Consejo de Estado acotaba al terreno de lo simbólico la utilización de tales calificativos, sin otra consecuencia jurídica que la del reconocimiento en sí mismo. En un momento de proliferación de demandas políticas de reconocimiento de identidades de todo tipo, no se puede menospreciar el valor que ello supone, aunque queda por ver qué otras consecuencias pueden derivarse del mismo.

Sin embargo, hoy el debate en torno al significado y alcance de la constitucionalización de España como nación de nacionalidades y regiones podría parecer superado, porque se ha impuesto en los sucesores de ciertos actores del pacto constituyente una lógica rupturista y no reformista de los difíciles equilibrios que contiene la Constitución en materia territorial, y que resume su art. 2. Estos planteamientos rupturistas abogan por la defensa ya sea de una nación cuya diversidad territorial no se materialice en el Estado autonómico como Estado políticamente compuesto, o bien de un Estado plurinacional de tipo confederal, cuando no directamente por el derecho a decidir la secesión de ciertos territorios por ellos mismos de forma unilateral.

\section{ALBERTO LÓPEZ BASAGUREN}

La Constitución española es, en este sentido, una pionera en la utilización de una terminología que enlaza directamente con la reflexión realizada en el CoE a la que me he referido más arriba. Es singular la terminología utilizada en dos sentidos diferentes. Por una parte, se aferra al término 'Nación española', en lugar de hacer referencia al Estado o al Reino, si se quiere. Pero por otra utiliza una terminología que yo calificaría, en el contexto de la transición en la que se elaboró el texto constitucional, de atrevida, aunque cautelosa, al mismo tiempo. Ciertamente, es llamativo el recurso al término 'nacionalidades', de claros ecos históricos (Pi i Margall), por una parte, que, por otra, enlaza directamente con la idea de las minorías nacionales. El recurso a ese término creo que debe ser entendido en el sentido del reconocimiento de la pluralidad 'nacional' de España. Aunque ello se haga recurriendo a un término que podríamos calificar de atenuado respecto al término 'nación' o 'minoría nacional' — que, por otra parte, este último, suele ser rechazado por los nacionalistas de comunidades integradas en el Estado-.

Es cierto que, al no haber tenido ningún efecto práctico relevante la distinción entre 'nacionalidades' y 'regiones', con carácter de permanencia, el fuerte potencial que suponía el uso de ese término ha quedado limitado al ámbito del 
reconocimiento simbólico de esa realidad 'nacional' plural. Un reconocimiento que, sin embargo, considero muy significativo.

A mi juicio, el uso del término nacionalidades junto al de Nación española, en los términos que se han señalado en estas líneas, tendría que haber evitado una interpretación de la terminología vinculada al reconocimiento de la condición 'nacional' en sentido única y exclusivamente político — referido a la titularidad de la soberanía-, reservando su uso, de forma exclusiva, al conjunto del pueblo español, identificado como Nación española. Habría que haber precisado que una cuestión es la relativa a la titularidad de la soberanía, sentido en el que la Constitución se refiere al pueblo español como Nación española, y otra el reconocimiento de otras realidades 'nacionales'; un reconocimiento que carece de connotaciones relativas a la titularidad de la soberanía y, por tanto, no supone la atribución de la titularidad del derecho de autodeterminación —exclusión avalada en el Derecho internacional — ni de derecho alguno a la secesión, como se deriva de la afirmación de la indisolubilidad del Estado establecida en la Constitución.

El uso del término 'nacionalidades' en el art. 2 de la Constitución enlaza con la consideración, acogida en el CoE, de que el concepto de 'nación', además de la imposibilidad de llegar a un concepto único, aceptado de forma general, tiene significados multívocos, no necesariamente vinculados a la titularidad de la soberanía o en los términos del antiguo 'principio de las nacionalidades'. Por ello es posible aceptar el uso del término 'nación' —o términos similares— para comunidades integradas en el Estado, que forman parte del pueblo español — por tanto, de la Nación española, en terminología de la Constitución - sin que ello sea incompatible con el uso del término en los arts. 1 y 2 de la Constitución. Que la Nación española sea 'única e indivisible' no impide el recurso a la terminología de nación cuando a ésta se le atribuyen otros significados distintos del de la titularidad de la soberanía y cuando no afecta a la indisolubilidad del Estado. Es la vía por la que optó la Cámara baja del Parlamento canadiense al aprobar, en noviembre de 2006 — por 266 votos frente a 16- la moción por la que se reconocía que «that the Québécois form a nation within a united Canada»; o es la que subyace al uso, ciertamente extendido, en el Reino Unido cuando se afirma «We are four nations in a single country».

Creo que por esta vía tendría que haber ido la interpretación del TC en relación con la cuestión planteada en el Preámbulo y en distintos artículos del Estatuto de Cataluña de 2006, que fue abordada en la STC 31/2010, de 28 de junio y que, a mi juicio, no se resolvió de forma adecuada.

El problema que se plantea entre nosotros es que, tanto quienes afirman la condición nacional (el sentimiento nacional, habría que decir, en términos del informe del $\mathrm{CoE}$ citado) de una determinada comunidad integrada en el Estado, como quienes la reservan, en exclusiva, al conjunto del pueblo español, comparten el mismo concepto reductivo de 'nación', en sentido estrictamente político, vinculado a la titularidad de la soberanía. El debate sobre estas cuestiones, por el contrario, pone de relieve que conviven diferentes significados de 'nación'; uno estrictamente político, en el sentido indicado, vinculado a la titularidad de 
la soberanía; y otro de carácter 'comunitario', por las características de una determinada comunidad —entre nosotros, fundamentalmente lingüístico-cultural, aunque hay casos, como el escocés, en el que esa identidad no reside, en lo fundamental, sobre características de esa naturaleza- que, aunque con derivaciones políticas, está desvinculado de la titularidad de la soberanía. Pero, siguiendo la orientación del debate en el CoE sobre esta cuestión, hay que reiterar que el reconocimiento de la existencia de un sentimiento nacional propio en una determinada comunidad no presupone la aceptación de su homogeneidad respecto a las características que la singularizan. Las sociedades modernas son profundamente plurales; una pluralidad que no puede ser marginada por el reconocimiento de la misma como 'nación'.

\section{ESTHER SEIJAS VILLADANGOS}

La Nación jurídico constitucional que se consigna en el art. 2 es una expresión sinónima a Estado, a Pueblo o a España. Por consiguiente, sus consecuencias son las que hemos derivado del concepto de Nación. Cuando el constituyente quiso abordar en el título preliminar la organización territorial del Estado, marcando unas directrices blindadas por el procedimiento de reforma agravado, y que luego se desarrollarían, con más o menos precisión, con más o menos voluntad de cierre o apertura, no dijo más que lo que se espera de un Estado, que se articule en torno a una unidad, que no se fragmente, porque con ello se perderían los atributos derivados de la estatalidad. Es esa unidad no fragmentable, indisoluble lo que constituye el fundamento del Estado que expresa a través de la Constitución la voluntad de sus ciudadanos. Aquí se acompaña de la expresión patria, adjetivada como común. La idea de patria se conecta a una virtud cívica, un énfasis de la posición de los ciudadanos de formar parte de un Estado, y se identifica con Constitución, como expresamente se hizo en 1812 (Argüelles). El problema de la utilización del término patria deriva de su conexión con la propaganda e ideología franquista, una rémora que muchos se empeñan en reavivar.

De cara a afrontar una distribución territorial del poder, el constituyente optó por la denominación de dos sujetos diferenciados semánticamente, como nacionalidades y regiones. Ambos términos aluden a dos comunidades culturales que pueden impulsar su conversión orgánica en Comunidades Autónomas, a través de unos sujetos explicitados en el título VIII, concretamente en el art. 143.1, a los que se marcará un iter con las distintas vías de acceso a la autonomía. Es tanta la importancia y la implicación de la Nación en el diseño de esa organización territorial, que es el interés nacional al que se apela para cerrar su diseño (art. 144). A nacionalidades y regiones la Constitución solo enfatiza el nexo que las une, su titularidad del derecho a la autonomía. Pero, en ningún caso marca la diferencia, ni cualitativa, ni cuantitativa entre ellas. 
¿Por qué, entonces, la obsesión por tildarse como Nacionalidad, en lugar de Región, o incluso de Nación? Si la Constitución guardó silencio sobre las consecuencias de llamarse Nacionalidad o Región, los Estatutos de Autonomía se han encargado de entregarse a una carrera desenfrenada por aumentar su ego, de la mano de describirse como Nacionalidad - Canarias—, incluso con el plus de nacionalidad histórica — Aragón, Andalucía, Illes Balears-, en lugar de Región -Castilla y León se define como Región de Europa y se enfanga en el primer artículo de su Estatuto reformado en reivindicar su contribución a la formación de España como Nación, mensaje para aquellos que buscan su fragmentación-, e incluso como Nación - Cataluña-.

Qué podemos decir sobre esta versión autonómica de «Los locos de Cannonball». Pues que se ha llegado a lo que parecía no concebirse. Por ahora, corría 2005 cuando se escribió, «ninguno se ha autodefinido como Nación» (Carreras). Pues antes de que estas palabras vieran la luz, el Estatuto de Cataluña de 19 de julio de 2006 abrió una nueva veda. El Tribunal Constitucional lo valoró cuatro años después, siendo para unos excesivamente comedido, exacerbadamente positivista y academicista (Voto particular de Gay Montalvo, $3 .^{\circ}$ ) o excesivamente tolerante maquillando una afirmación que estaría en flagrante contradicción con la Constitución (Rodríguez Arriba, $4{ }^{\circ}{ }^{\circ}$. El tribunal falló que «Carecen de eficacia jurídica interpretativa las referencias del preámbulo del Estatuto de Cataluña a "Cataluña como nación" y a "la realidad nacional de Cataluña" y que no es inconstitucional hablar de símbolos nacionales, si se entienden como propios de una nacionalidad». El propio Tribunal se contradice a sí mismo con esa manifestación al haber rechazado aquellas normas que desconozcan o induzcan al equívoco respecto a la indisoluble unidad (STC31/2010, FJ 12), es decir, a su concepción de Nación. La singularidad de Cataluña, sus asimetrías, no pueden borrarse, ni anularse en un Fallo del Alto Tribunal, pero tampoco puede alentarse una demagogia populista que convierte cualquier expresión en una tea incendiaria. La nacionalidad de Cataluña y de otras comunidades que así se consideren no puede construirse solo y exclusivamente como reacción a, o antítesis de. Ahí se genera un desgaste que llevará indiscutiblemente a la pérdida de su propia esencia, de su propio valor como nacionalidad cultural, como comunidad que ha sumado, liderado y consolidado jurídicamente una posición dentro del Estado, de la Nación española.

\section{En el proceso de integración supranacional que se inició en Europa tras la Segunda Guerra Mundial ¿qué significado se atribuyó a la idea de supranacionalidad? ¿En qué medida se entendió como la superación de las ideas de nación y nacionalismo?}

\section{BENITO ALÁEZ CORRAL}

Aun partiendo de la polisemia del término supranacionalidad, en un contexto político como el europeo, basado mayoritariamente en el concepto de 
Estado-nación soberano, la integración supranacional pretende ser un modelo de construcción política y jurídica que vaya más allá de los confines territoriales de aquél, transfiriendo (el ejercicio) de poderes tradicionalmente inherentes al concepto de soberanía política del Estado y por tanto, en cierta forma, poniendo en cuestión dicha soberanía estatal. A diferencia de la cooperación internacional a través de los Tratados y las Organizaciones Internacionales, que no pone en cuestión la soberanía del Estado - en la medida en que a través de la denuncia o incluso el incumplimiento con la consiguiente asunción de responsabilidad internacional, se pude poner fin a la cooperación y excluirse de aquellos compromisos internacionales con los que no se esté de acuerdo-, la integración supranacional presupone y ha ido desarrollando en buena medida un modelo de adopción de decisiones por mayorías (cualificadas normalmente) que conlleva inevitablemente una limitación del ejercicio de la soberanía.

Otra cuestión, distinta, es la relativa a la titularidad de ese poder supranacional que ejercen las instituciones europeas. Aunque por emulación de las fórmulas soberanistas de los Estados-nación que componen la Unión Europea, se tiende a identificar la democracia a nivel Europeo con la construcción de un pueblo (demos) europeo, lo cierto es que esta aspiración se topa con dos grandes obstáculos jurídicos: en primer término la ausencia (aún) de reconocimiento por parte de los Estados miembros de soberanía jurídica de la Unión Europea, en el sentido de posesión por ésta de la competencia sobre las competencias, soberanía que se pudiera imputar a ese demos europeo al modo y manera que se hace en los Estados miembros con sus respectivos pueblos o naciones titulares de la soberanía de cada Estado. Y en segundo término, aún en la hipótesis de que se afirmase la existencia de esa soberanía jurídica de la Unión como ente y se ejerciese la misma a través de sus instituciones con la primacía del Derecho de la Unión como efecto último salvaguardado por el Tribunal de Justicia de la Unión, todavía quedaría por determinar si esa soberanía jurídica se debe imputar políticamente a un demos europeo entendido como un único demos supranacional, o a un demos complejo, compuesto no sólo por ciudadanos europeos individualmente considerados, sino también por los Estados miembros, siguiendo un modelo híbrido federal y confederal a la vez. Me inclino por pensar que éste sería el entendimiento que, de afirmarse, se desprendería en el mejor de los casos, a día de hoy, de los tratados constitutivos de la Unión Europea.

\section{PALOMA BIGLINO CAMPOS}

La razón principal por la que, a inicios de los años 50 del pasado siglo, comenzó la integración europea fue, precisamente, superar los nacionalismos que habían conducido a la implantación del nazismo y del fascismo y al estallido de la segunda guerra mundial.

El preámbulo del Estatuto del Consejo de Europa, de 1949, afirma claramente que la consecución de la paz, basada en la justicia y la cooperación 
internacional, es de interés vital para la preservación de la sociedad humana y de la civilización. Para acabar con los conflictos armados, es necesario lograr una unión más estrecha entre los países de Europa, basada en valores inherentes al sistema democrático tales como el imperio del Derecho y el respeto a los derechos fundamentales.

Esta voluntad está todavía más clara en el preámbulo del Tratado de la Comunidad Europea del Carbón y del Acero de 1951. Siguiendo muy de cerca los planteamientos de la declaración Robert Schuman, dicho texto se propone superar las rivalidades seculares entre Estados, divididos durante largo tiempo por sangrientas escisiones, para dar lugar a una fusión de los intereses esenciales de los países miembros. Esta etapa se concibe, además, como un primer paso para lograr una comunidad más profunda entre pueblos.

Es cierto que entre el Consejo de Europa y los precedentes de la Unión Europea existían y siguen existiendo profundas diferencias. Así, mientras el primero busca incrementar la integración política respetando, al mismo tiempo, la soberanía estatal, la segunda sigue actuando más en el ámbito económico, restringiendo de forma incisiva el poder inherente a los Estados. Ahora bien, a pesar de estas divergencias, ambas organizaciones nacen para impedir excesos fundamentados en la idea de nación o de nacionalismo.

Para ilustrar este extremo, baste con recordar la decidida intervención del TEDH en defensa de quienes no han obtenido amparo en las jurisdicciones estatales, quizás por tener en contra el fallo de la opinión pública interna. También puede ponerse como ejemplo la razón de ser de dos nociones básicas de la integración como son la primacía y la eficacia directa del Derecho de la Unión. Recordemos que, según la jurisprudencia del TJUE, ambas exigen a los Estados lealtad a la integración que ellos mismos han creado, de manera voluntaria y limitando su propia soberanía, obligándoles a anteponer la aplicación homogénea de las normas de la Unión a la defensa unilateral de sus intereses.

\section{ROBERTO BLANCO VALDÉS}

Aunque obviamente se trata de un tema complejo, por su extraordinaria trascendencia histórica, como para resolverlo en una respuesta breve, no cabe duda de que la creación en 1957 de la Comunidad Económica Europa (CEE) y de la Comunidad Europea de la Energía Atómica (EURATOM), tras la firma en 1951 del Tratado de París por el que se constituía la Comunidad Europea del Carbón y del Acero (CECA), está relacionada directamente con el gran trauma que supuso en todo el mundo, pero de forma muy especial en Europa, la Segunda Guerra Mundial. No es por eso casual que se instituyese, primero, una entidad dirigida a regular dos productos que eran básicos a mediados de los años cincuenta del siglo pasado en las economías de los países que se comprometían en la CECA (el carbón y el acero) y que pocos años después se avanzase en la creación 
de una entidad reguladora de todo lo relativo a la producción segura de energía atómica en el espacio europeo y de un mercado común en el que se unían, entre otros, dos de los Estados que habían tenido un protagonismo extraordinario en la historia europea desde el último tercio del siglo XIx: hablo, obviamente, de Francia y de Alemania, enfrentados primero en la Guerra Franco-Prusiana (18701871) y posteriormente en la Gran Guerra y en la Segunda Guerra Mundial.

Los nacionalismos, que habían sido un factor desencadenante esencial de todos esos conflictos, hubieron de someterse a un ejercicio de contención y de autocrítica para poder afrontar el proceso de creación de entidades supranacionales que suponían la colaboración entre Estados, con lo que ello significaba de renuncia a un entendimiento nacionalista y chauvinista de las relaciones internacionales y del propio concepto de nación. En todo caso la pervivencia del nacionalismo explica en gran medida el retraso del Reino Unido en incorporarse a las Comunidades Europeas, así como, también, su posterior presencia en ellas, siempre marcada por una peculiar posición respecto de algunas de las grandes decisiones que marcaron el desarrollo político, económico e institucional de la CEE.

De lo dicho no cabe deducir, sin embargo, a mi juicio, que el proceso de integración europea se entendiese en toda su larga fase inicial, y desde luego, no antes de la firma del tratado de Maastricht en 1992, como un intento, o un proyecto, de superación de la idea de nación, aunque, sí, como ya he señalado, de aquel nacionalismo agresivo y en algunos casos expansionista que tuvo gran presencia en algunos Estados europeos entre el último tercio del siglo xix y el final de la Segunda Guerra Mundial. Un nacionalismo que provocó docenas de millones de muertos y una destrucción sin precedentes en la historia de la humanidad y que vacunó a algunas grandes naciones contra el peligro nacionalista, aunque no a todas, como habrían de demostrarlo trágicamente las guerras terribles de Yugoslavia entre 1991 y 2001, con nuevos e increíbles episodios de matanzas en masa y limpiezas étnicas.

De hecho, el avance del proceso de integración europea es ininteligible sin tener en cuenta el decisivo papel de las élites políticas de algunos Estados nacionales — de Alemana y Francia, muy particularmente- que, desde sus respectivas posiciones soberanas y sin renunciar a ellas en ningún caso, impulsaron la adopción de acuerdos que iban a significar la cesión de poderes a entidades supranacionales —el Consejo de Ministros, la Comisión Europea el Parlamento Europeo y la Cortes de Justicia Europea - en ámbitos esenciales como la política agraria común (PAC), el mercado interior mediante la progresiva supresión de barreras arancelarias, una política de comercio común y más tarde una política exterior y de seguridad común (PESC).

\section{JOSEP M. ${ }^{a}$ CASTELLÁ ANDREU}

Hay coincidencia en mostrar el proceso de integración europea que empezó con la CECA y la CEE, desde la declaración Schuman de 1950, como voluntad de 
superación de los nacionalismos que habían conducido a la segunda guerra mundial. Por eso Mitterrand pudo afirmar que el nacionalismo es la guerra. Pero ello no implicaba ni implica la superación de la idea de nación, entendida en este contexto como Estado-nación y como espacio geográfico e histórico donde el pueblo se autodetermina democráticamente. $\mathrm{Ni}$ tampoco supone la sustitución de las naciones por una Unión Europea dotada de identidad nacional que reemplaza lo que ha cimentado a lo largo de los siglos la unidad estatal. Es más, parece que la Unión ha supuesto la salvación del Estado-nación, no su final (Milward). Otra cosa es que haya «domesticado» a dichos estados. El proceso de integración ha basculado siempre entre lo nacional o intergubernamental y lo supranacional o con vocación federalista. El resultado es un frágil equilibrio entre ambos polos, con tensiones y acuerdos que permiten mantener la integración como proceso dinámico, más que como producto acabado. El consenso o espíritu de compromiso entre estados y entre familias políticas ha sido clave para ir configurando las sucesivas fisonomías de la Unión.

La Unión Europea es una unión de Estados, dotados de identidad nacional, que va más allá de la identidad constitucional que el Tratado de la Unión asume y respeta (art. 4.2). Antes, el Tratado de Maastricht ya había introducido el principio de subsidiariedad. Por ello el constitucionalismo o la gobernanza multinivel se plantean, en primer lugar, en términos funcionales, de cooperación e interacción interinstitucional. Pero ello implica también, en segundo lugar, una comunidad de valores, principios y derechos, explicitados en el art. 2 del TUE y en la Carta de Derechos Fundamentales, además de la pertenencia de todos los Estados miembros de la Unión al Consejo de Europa.

La identidad europea no es equiparable a la identidad nacional de los Estados miembros. Los valores y principios que identifican la Unión Europea se mueven sobre todo en el plano de los factores de identidad del constitucionalismo liberal democrático (Estado de derecho, democracia, derechos fundamentales, separación de poderes, libertad, igualdad, dignidad, solidaridad). Tales factores no se pueden parangonar con los elementos de identidad nacional de los Estados-nación, aunque haya un fondo histórico, de civilización y religioso en gran medida compartido por los pueblos europeos que, significativamente, no quedó reflejado en el Preámbulo del proyecto de Tratado constitucional. Por ello, la Unión Europea es comunidad política y no mera organización internacional.

Cada vez que se ha planteado Europa como Estado constitucional y federal, o la Europa de las regiones, como superación de la Europa de los Estados-nación, la UE ha tenido que afrontar crisis profundas y han salido voces recordando que los Estados son las partes constitutivas de la Unión, que no hay un pueblo europeo como sujeto constituyente, que los pueblos de los Estados son los soberanos y que no se puede dar por descontado el consenso para dichos propósitos superadores de los Estados: De Gaulle, Thatcher, los cuerpos electorales francés y holandés, el Tribunal Constitucional alemán y, en su versión más radical, el Brexit. 


\section{ALBERTO LÓPEZ BASAGUREN}

En el proceso de integración europea la suprancionalidad tiene el carácter de supraestatalidad; es decir, referencia a las diferentes nacionalidades en la acepción de la palabra que la identifica con el conjunto del pueblo que está en la base del Estado. Hay que tener en cuenta que la integración europea es, en su origen, un proceso europeo occidental, exclusivamente, y que se consideraba que la cuestión de las minorías nacionales era un problema de Europa central y oriental. El origen de la integración europea se sitúa, por tanto, en el parámetro de la superación de los Estados-nación y del nacionalismo expresado por éstos, porque, tras las dos grandes guerras del siglo Xx, hay conciencia de que el nacionalismo ha provocado las mayores tragedias en el continente. Como digo, ese nacionalismo, en Europa occidental, es el nacionalismo de los Estados-nación. Al terminar la II guerra mundial, se considera que en Europa occidental no hay problema de nacionalismos internos. Hay problemas puntuales en la delineación de fronteras entre algunos países; pero no se trata de problemas de minorías nacionales, como en Europa central y oriental. Se considera, en cualquier caso, que en Europa occidental la protección de los derechos humanos es garantía frente a cualquier problema que se plantee en ese ámbito. Pero, junto a la conciencia sobre los peligros que contiene el nacionalismo de los grandes Estados-nación, también está la conciencia de los riesgos de desestabilización que contiene el nacionalismo de las minorías nacionales internas a los Estados, como se había puesto en evidencia en el periodo de entreguerras y en su contribución a la desestabilización del continente que desencadenó la segunda guerra mundial.

En ese sentido, la integración europea abre el camino a la superación de los nacionalismos y, en esa dirección, a la atenuación de la propia idea de nación. En la medida en que los Estados ceden soberanía a la Comunidad Europea, los Estados ya no son los detentadores de una concepción ilimitada y autosuficiente de la soberanía. En estas condiciones, la arrogancia de los Estados, vinculada al nacionalismo, deja de ser viable entre los Estados miembros. Se impone la idea de la decisión junto con los demás en lugar de la decisión autónoma de cada uno de los Estados. Los conflictos se canalizan en el interior de la CE, entre Estados que tienen que decidir conjuntamente. La confrontación externa entre Estados desaparece, necesariamente. La integración europea, al plantear la colaboración frente a la confrontación, es la mayor contribución a la superación del nacionalismo vinculado a los Estados-nación. Ya desde la Declaración de Schuman (1950) esa idea es el motor de la integración europea.

\section{ESTHER SEIJAS VILLADANGOS}

Aquí podemos destacar un efecto boomerang. Lo que se concibió como la solución de la Primera Guerra Mundial, pensemos en la creación de Yugoslavia y Checoslovaquia, se volvió en contra frontalmente con la Segunda Guerra Mundial. Los 
nacionalismos totalitarios que la protagonizaron y las naciones homogéneas cultural y socialmente que trataron de imponer, con sus presupuestos antidemocráticos y de extrema violencia, se trataron de superar con un nuevo orden cuyo cénit fue la creación de la Europa común. El germen de la Unión Europea está en tratar de evitar ese conflicto bélico. Controlar la producción de carbón y acero era, en la mente de Schumann y Monnet, cercenar las posibilidades de librar una nueva batalla. La idea de crear intereses comunes es la salida para tratar de superar exaltaciones exacerbadas y peligrosas de los valores de naciones culturales homogéneas. Lo que quiere dejar atrás la Europa común es el recurso a las diferencias como arma opresora de otras naciones, de otros estados. Se buscaría una contención de la nación cultural, avalada por la cooperación de las naciones jurídico-constitucionales, de los Estados. Esa estrategia va aderezada por la construcción de una cultura europea común (Häberle), que se perfile como referente para otros patrones u otros modelos. En la que se enfatice el valor de los derechos, el respeto a la libertad y a la tolerancia y que se busque la cooperación.

En ese contexto el término de supranacionalidad fue un neologismo que se consolidó en el art. 92.2 del Tratado de París de 1951, creador de la Comunidad Europea del Carbón y del Acero (CECA), al regular las funciones de la Alta Autoridad, concebidas como ajenas a las instrucciones de los gobiernos, absteniéndose de todo acto incompatible con el carácter supranacional. Su conversión en principio estructural de la nueva Europa parte de su asimilación a la renuncia de determinados aspectos de la soberanía nacional, como la potestad de legislar o de acuñar moneda (Bodino). A partir de ahí, se ha de diseñar un camino que se oriente a la plenitud de tal integración de la mano de la creación de órganos que solo representen a los intereses comunitarios y de la inmediatez de sus decisiones sobre los Estados y sobre los ciudadanos. Los requisitos trazados: unos objetivos comunes, una estructura institucional, amplias competencias. Pero en este camino, las dificultades han sido notables. La cooperación nunca ha sido plena y ha sobrevivido una desconfianza entre los Estados. En el avance expansionista de la Unión se ha perdido buena parte de su esencia, estoy pensando en las derivas totalitarias de Hungría o Polonia. Con todo, la mayor decepción para este proyecto europeo común ha sido la separación de Reino Unido. Por otro lado, la Unión, paradójicamente, se convierte en el destino anhelado por aquellos que quieren separarse de sus Estados de origen, pensemos en Escocia o Cataluña.

6. Setenta años después ¿se puede seguir entendiendo del mismo modo la supranacionalidad europea? ¿Cómo se explica boy la relación entre la idea de nación y el proyecto supranacional europeo?

\section{BENITO ALÁEZ CORRAL}

La supranacionalidad con la que se constituyeron las originarias comunidades europeas (del carbón y del acero, de la energía atómica y económica) ha 
evolucionado, sin lugar a dudas en términos tanto puramente jurídicos como políticos. De una parte, ya muy tempranamente el Tribunal Justicia de las entonces Comunidades Europeas comenzó afirmando el carácter de comunidad jurídica autónoma del orden legal creado por los tratados de las tres comunidades europeas, superando su mera concepción como organizaciones de cooperación internacional, que se integra en el sistema jurídico de los Estados miembros (Asunto Flaminio Costa vs ENEL). Al mismo tiempo se afirmó, en consonancia con ello, el principio de primacía del derecho derivado de las instituciones creadas por dichas organizaciones europeas, que prevalecerá sobre cualquier disposición interna de los Estados miembros, incluidas las constitucionales (Asunto Internationale Handelsgesellschaft v Einfuhr- und Vorratsstelle Getreide), lo que inicia el camino de la tensión y en ocasiones diálogo con las instituciones judiciales de los Estados miembros que garantizan la supremacía constitucional y, con ello, la soberanía jurídica del Estado-nación, entendida ésta como competencia sobre las competencias.

De otro lado, en el ámbito político, la integración entre los Estados miembros se ha intensificado cada vez más, no solo porque se amplían los ámbitos de competencia de las Comunidades Europeas, así como los ámbitos en los que las decisiones se toman por mayorías (cualificadas en muchos casos, ciertamente, pero mayorías al fin y al cabo), sino porque la integración se traslada al ámbito político con la intención de ir construyendo paulatinamente una comunidad política, la Unión Europea creada en 1992, con una ciudadanía europea que tendría que ser la expresión de la existencia de un demos europeo (se conciba éste en términos unitarios o grupales). Todo ello en buena medida siguiendo el modelo de construcción del sujeto nacional de la soberanía y su configuración democráticas propios del Estado nación.

Sin embargo, no creo que se esté cerca de conseguir este objetivo de construcción de un demos europeo que se superponga a los pueblos/naciones de los Estados miembros por varias razones. De una parte, porque hay dos almas políticas en tensión en la caracterización de este sujeto colectivo europeo: una federal vinculada a la representación política de los ciudadanos europeos, y otra confederal vinculada a la representación territorial de los Estados miembros. Una y otra debieran combinarse armónicamente sobre la base de un principio constitutivo común de ese demos complejo al que se atribuiría la soberanía jurídica de la Unión (competencia sobre las competencias), pero realmente no lo hacen, sino que se contraponen haciendo el alma confederal (intergubernamental) de freno del alma federal de ese demos europeo. De ahí que se esté hablando constantemente de un déficit democrático de la Unión Europea, que en el fondo creo que no es la expresión sino de un déficit de demos europeo, más que de participación democrática, o, en otras palabras, de construcción de un sujeto colectivo de la soberanía europea, en los términos y por las razones que se han expuesto.

De otra parte, porque la afirmación de un demos europeo, se conciba éste como se conciba, solo tiene sentido para culminar la construcción de esta 
supranacionalidad con la atribución al mismo de la soberanía (jurídicamente hablando), es decir, la competencia sobre las competencias. Pero, a pesar de que en su momento, en la elaboración del Tratado de Roma de 2007 por el que se establecía una Constitución para la Unión Europea, se discutió que la Unión fuera perpetua y no cupiese abandono unilateral de la misma, el procedimiento del Brexit y el tenor literal del vigente art. 50 TUE ponen de relieve que la última palabra de la pertenencia a la Unión sigue en manos de los Estados miembros, lo que dificulta afirmar que la soberanía jurídica esté residenciada en la Unión y la misma se pueda imputar a un demos europeo.

\section{PALOMA BIGLINO CAMPOS}

Por las razones que he expuesto en la contestación a la primera pregunta de este cuestionario, me parece más preciso hablar de integración europea que de supranacionalidad europea. En efecto, ni se puede hablar de una nación europea ni es conveniente hacerlo.

Es cierto que, en contra de lo que afirman los euroescépticos, muchos pueblos de nuestro continente han tenido una historia común y han estado sometidos, a veces, al mismo poder político. También es verdad que compartimos un patrimonio ideológico que no sólo nos identifica frente a otros continentes, sino que se refleja en los ordenamientos jurídicos de los Estados. Es claro que nuestras constituciones se parecen, pero también lo hacen los códigos civiles, penales y mercantiles.

Esta identidad podría llevarnos a hablar de un pueblo o de una nación europea, pero sólo en sentido sociológico y no en términos jurídico-políticos. Tampoco esto último me parecería conveniente, ya que sería poco compatible con el pluralismo territorial que caracteriza a una estructura territorial compleja, como es la Unión. Servirse de dicho lenguaje podría reforzar los argumentos de quienes, como los partidarios del Brexit, rechazan los lazos comunes generados por la integración fundándose en la idiosincrasia, mucho más evidente, que corresponde a cada uno de los pueblos europeos.

Por similares razones, me parece oportuno subrayar el papel que juega la noción de ciudadanía europea en la integración. Como he afirmado anteriormente, esta idea es inherente a la democracia contemporánea, porque subraya la posición de los individuos en el sistema político, al hacerles portadores de derechos subjetivos, no sólo frente a la Unión sino también frente a los Estados miembros.

Desde este punto de vista, me parece que el proceso de integración y la creación de la ciudadanía europea siguen siendo fundamentales para los objetivos que ambas se proponían alcanzar desde sus orígenes, esto es, asegurar la paz y el bienestar de las personas, en el respeto al principio democrático, el Estado de Derecho y los derechos fundamentales. 
La historia de la integración no ha sido lineal, como no lo es ningún proceso histórico. Ha tenido vaivenes, donde se han alternado momentos de grandes esperanzas con severos retrocesos. Todavía tenemos muy reciente la falta de sensibilidad demostrada por algunas instituciones europeas ante las graves dificultades que la crisis de 2007 generó especialmente en el sur de Europa. Ahora bien, si observamos con más detenimiento la evolución que ha tenido la Unión en estos cincuenta años, debemos concluir que dichos acontecimientos han sido un paréntesis, porque jamás en la historia moderna de Europa ha existido un período tan largo de paz y prosperidad.

A la hora de hacer valoraciones acerca de la integración, hay que ser realista. Para algunos, impone restricciones que son contrarias a la idea de democracia, porque limitan la voluntad popular que se expresa a través de los parlamentos nacionales. En España, estas críticas se agudizaron cuando, por exigencias de la integración, hubo que reformar el art. 135 de la Constitución de forma repentina. Ahora bien, ni se puede juzgar todo un proceso por una sola de sus etapas, ni dichos acontecimientos se pueden valorar de forma aislada, sin tener en cuenta todo lo que los rodea. Es evidente que la Unión ha impuesto, e impondrá, límites a los Estados. Pero muchos de estos límites son imprescindibles para que prosiga la forma de vida que caracteriza a los europeos.

Hay veces que las instituciones nacionales, por muy representativas que sean, yerran. La experiencia europea demuestra que, desde el poder, es posible manipular a los ciudadanos y conseguir que la mayoría vulnere los derechos de todos, sin que las instituciones nacionales sean capaces de detener dichos abusos. Antes se ha señalado que las instituciones europeas también cometen errores y ponen en riesgo la propia integración. Ahora bien, la interacción entre Estados y poderes de la Unión constituye, de por sí, una garantía destinada a asegurar que esos problemas no se produzcan y que, de darse, puedan subsanarse.

Hay ejemplos concretos de las ventajas de esta interacción. La reacción de la Unión ante los excesos de las mayorías en Polonia y Hungría quizá no haya sido lo decidida que debería haber sido. Ahora bien, por ahora ha resultado bastante más efectiva que los límites impuestos por el Derecho interno. La actuación de la Unión durante la pandemia generada por el Covid-19 demuestra que, esta vez, los países de la Unión han sido capaces de ir más allá de sus intereses a corto plazo y de ceder parte de sus competencias y de sus fondos en favor de las instituciones de la Unión, únicas capaces de dar respuesta a los problemas, cuando estos no conocen fronteras.

\section{ROBERTO BLANCO VALDÉS}

En coherencia con lo que acabo de apuntar es indudable que desde la firma del Tratado de Roma en 1957 se ha producido un cambio sustancial en la idea de supranacionalidad que impulsó en su día la creación de las Comunidades 
Europeas. La firma del Acta Única Europea (1986), del Tratado de la Unión Europea (1992), del Tratado de Ámsterdam (1998), del Tratado de Niza (2001) o del Tratado de Lisboa (2008) supusieron un avance sustancial en la progresiva consolidación del proyecto de una futura federación europea. Incluso, y pese a su fracaso final, el proceso conducente a la elaboración del Tratado por el que establecía una Constitución para Europa, conocido como Constitución Europea, marcó un punto de inflexión en la idea de construir una Europa federal, que ha permanecido como un proyecto a abordar en el futuro, aunque es verdad que hoy no se dan ni de lejos las condiciones para volver a plantearse una meta tan ambiciosa. En tal sentido, la salida de Gran Bretaña de la UE, sin duda el hecho político más relevante en la historia del proceso de integración europea desde la firma del Tratado de Roma, ha tenido una doble consecuencia: de un lado, ha eliminado uno de los principales obstáculos que se habían venido oponiendo a la profundización en el proceso de integración, pero, de otro lado, ha sentado un precedente que podría servir de ejemplo a algunos otros países europeos que hoy manifiestan una abierto desacuerdo con algunos de los pasos dados por las instituciones de la UE.

Pero ese proceso de progresiva -e, incluso, intensa integración-, que no responde ya solo a la idea inicial de volver a evitar cualquier posibilidad de enfrentamiento violento entre las naciones europeas, sino que va mucho más allá, no ha supuesto, desde luego, ni de lejos, la desaparición de la idea de nación. El Estado-nación sigue siendo en todo el planeta, y desde luego en todo Occidente, la entidad básica de convivencia entre ciudadanos que se sienten de un mismo país, hablan en general una misma lengua (con algunas excepciones, como Bélgica o Suiza y, desde un punto de vista muy diferente, España, donde hay lenguas regionales pero también una lengua común) y comparten unas mismas instituciones e intereses. Por decirlo de otro modo, y ya para terminar, Europa no es hoy más que una unión de Estados por la ausencia de una auténtica ciudadanía europea y es difícil que llegue a ser una unión federal mientras ese vínculo europeo no se fortalezca hasta el punto de poder superar las identidades nacionales, hoy muy potentes, pese al intenso proceso de unión política y económica que ha supuesto la Unión, sin duda uno de los acontecimientos más relevantes de la historia contemporánea de Europa.

\section{JOSEP M. ${ }^{a}$ CASTELLÁ ANDREU}

Hoy el propósito por el que nacieron las comunidades europeas — la paz y la reconciliación entre pueblos europeos- parece logrado y por ello superado como elemento movilizador de las actuales generaciones en favor del proceso de integración. Pero, al mismo tiempo, desde el inicio de las Comunidades, se ha tratado de legitimar la integración en logros a primera vista funcionales que se suelen resumir en el bienestar de los ciudadanos europeos: la PAC, la moneda única, la 
libre circulación, la ayuda financiera entre los Estados sobre todo visible en momentos de crisis como la actual y la anterior... Tales actuaciones, de gran relevancia para la vida de los ciudadanos y los estados, responden a objetivos que van más allá de lo funcional o tecnocrático, e implican la consolidación progresiva de un espacio político común, de una verdadera comunidad política en la que actúa la solidaridad entre los pueblos de Europa y el respeto a unos valores políticos y constitucionales compartidos. Véase el papel cada vez mayor que las instituciones de la UE asumen como límite y control de las actuaciones de gobiernos irrespetuosas con el Estado de Derecho. Como ha afirmado Krastev recientemente, el sobrevivir conjuntamente y de manera flexible a las distintas crisis habría hecho percibir a los europeos que formamos parte de una misma comunidad política.

A veces, sin embargo, puede dar la impresión que algunas de las actuaciones políticas no se hacen de manera suficientemente respetuosa con ciertos factores de identidad nacional o con la nación misma, que siguen siendo importantes para porciones nada desdeñables de las poblaciones, aunque haya líderes europeos que tiendan a obviarlo. Ello lleva a que algunos estados aleguen esta contradicción axiológica o la pérdida de soberanía nacional para justificar el rechazo a iniciativas de la UE, como evidenció la crisis de los refugiados. Los populismos se sirven de este malestar y sentido de desarraigo de partes de la población, pero en todo caso muestran una situación existente y deberían estimularnos a afrontarla, tomando en serio las causas. La retirada del Reino Unido no ha significado, como era previsible, aunque no se quisiera ver, el fin de las tensiones entre defensa de valores e intereses nacionales y los de las instituciones de la Unión, ya que son constitutivas de su pluralidad más profunda.

El moto de la Unión — «unidos en la diversidad»— apela, en su aparente modestia, precisamente a dos aspectos fundamentales: a lo práctico y funcional, esto es, a la capacidad de la Unión de servir o ser útil a los ciudadanos y a las sociedades europeos, y también al pluralismo europeo. Esto último frente a la tentación de promover desde arriba una homogeneidad impostada, la cual despierta reacciones adversas en sectores de la población de los estados de Europa. Los líderes europeos, ante cualquier reforma en las estructuras institucionales, deberán contar con ambos aspectos si quieren que la Unión goce de amplia legitimidad entre los pueblos europeos.

\section{ALBERTO LÓPEZ BASAGUREN}

La integración supranacional europea sigue siendo el instrumento más eficaz para contener el desarrollo de los nacionalismos, tanto los nacionalismos de Estado como los de las minorías nacionales que forman parte de aquellos. Como se viene evidenciando en los últimos tiempos, las crisis de la integración europea revitalizan la dinámica nacionalista y, a la inversa, los nacionalismos ven en la UE el mayor freno a sus pretensiones. Lo hemos visto con el Front nationale francés, 
entre otros movimientos nacionalistas, o con las crisis de Hungría y Polonia. El mayor riesgo para la continuidad del proceso de integración europea es el resurgir de nacionalismos de Estado. Por esa razón, aunque la realidad europea actual es muy diferente de la de los primeros años de la posguerra, especialmente tras las sucesivas ampliaciones a Europa central y oriental, la integración supranacional europea sigue teniendo un profundo significado antinacionalista. El debate en el Reino Unido entre partidarios del Brexit y contrarios a él lo ha vuelto a poner de manifiesto: se ha tratado, en gran medida, de un debate entre un nacionalismo inglés orgulloso de sí mismo y una visión integradora europea. La división por cohortes de edad, por nivel de estudios y por nivel económico entre unos y otros ha sido, en este sentido, muy significativa.

El proceso de integración supranacional europeo afronta retos muy diferentes a los de la década de los cincuenta del siglo xx y décadas inmediatamente posteriores. Pero en su base sigue existiendo el elemento de la superación de la idea fuerza de la identidad nacional como un mundo cerrado y autosuficiente. El gobierno conjunto, junto a los demás, la integración, la superación de las fronteras interiores son un antídoto frente a los nacionalismos.

Al mismo tiempo, la idea de integración supranacional europea tiene que ser un freno a los intentos de proliferación de nuevos Estados, creados sobre la base de la independencia de comunidades territoriales que forman parte de Estados integrados en la UE, en la medida en que esa proliferación se orienta en una dirección contraria a la de la integración supranacional y en la medida en que, en esa dirección, crea dificultades añadidas a la gobernabilidad de la organización supranacional.

Pero ello requiere, por una parte, garantizar la protección de las minorías nacionales en el seno de los Estados que forman parte de la UE; una tarea a la que ha dedicado sus esfuerzos, complementariamente a la UE, el CoE. Y, además, requiere que en el seno de la UE se articule un papel más efectivo de los territorios con autonomía política en el interior de los Estados miembros (las denominadas Regions with Legislative Power) que les reconozca un mayor protagonismo en el entramado de gobierno de la organización supranacional. Porque, en caso contrario, se estará reforzando la paradoja de que la integración europea impulsa la conveniencia de convertirse en Estado independiente dentro de la UE, especialmente, a la vista del status de los pequeños Estados miembros en su seno.

\section{ESTHER SEIJAS VILLADANGOS}

La transformación de Nación/Estado a Estado/miembro es la clave de este cambio. La Unión europea es hoy una Unión de Estados miembros, no un Estado supranacional, que protagoniza la vida política nacional, marcada por una debilidad institucional de sus parlamentos. El peaje a pagar en esa transformación de los Estados nación a Estados miembros ha sido el cuestionamiento de sus pilares 
democráticos, abanderado por populistas y tecnócratas (Seijas, 2012). Esta percepción donde realmente ha calado es en los ciudadanos.

El Tratado de 2005, tras la negativa a su aprobación por franceses y neerlandeses, reformulado como Tratado de Lisboa, asume una naturaleza bifronte desde la paradoja de su descripción como Tratado Constitucional: «legalmente un Tratado, políticamente, una Constitución» (Chirac).

La Europa de nuestros días se caracteriza por una consolidación nacional, jurídicamente forjada sobre una nación cultural europea, obligada a pervivir con reivindicaciones nacionalistas que se autoafirman, precisamente, en esa lucha frente a la idea del Estado Nación, al que paradójicamente aspiran.

$$
* * *
$$

TITLE: Academic survey about nation and supranationality

AвSTRACT: In this academic survey a group of Constitutional Law Professors answer some questions about the concept of nation, its role in the bistorical evolution of constitutionalism and of nationalist movements, and its relation nowadays with the idea of constitution; about the meaning of the term "nation" in the Spanish constitution and of the term "nationalities»; and finally about the idea of supranationality that defines the European integration process and its relationship with the concept of nation.

RESUMEN: En esta encuesta un grupo de profesores de Derecho Constitucional contestan un conjunto de preguntas sobre el concepto de nación, el papel que ha desempeñado tal concepto en el desarrollo bistórico del constitucionalismo y en el desarrollo de los movimientos nacionalistas, y la relación actual que mantiene con la idea de constitución; sobre el significado del término "nación» en la constitución española, y el del término "nacionalidades»; y, finalmente, sobre la idea de supranacionalidad que define el proceso de integración europea y su relación con el concepto de nación.

KEY WORDS: nation, nationalism, nationalities, supranationality.

PALABRAS CLAVE: nación, nacionalismo, nacionalidades, supranacionalidad. 